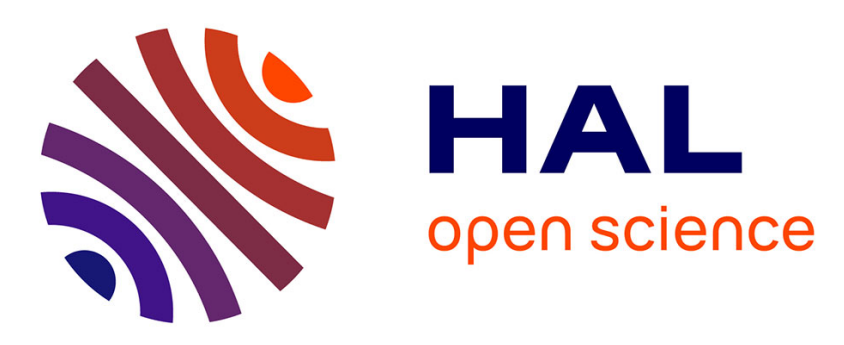

\title{
Estimation of Soil Evaporation and Vegetation Transpiration Using Two Trapezoidal Models From MODIS Data
}

Yazhen Jiang, Ronglin Tang, Xiaoguang Jiang, Zhao-Liang Li, Caixia Gao

\section{- To cite this version:}

Yazhen Jiang, Ronglin Tang, Xiaoguang Jiang, Zhao-Liang Li, Caixia Gao. Estimation of Soil Evaporation and Vegetation Transpiration Using Two Trapezoidal Models From MODIS Data. Journal of Geophysical Research: Atmospheres, 2019, 124 (14), pp.7647-7664. 10.1029/2019JD030542 . hal02377702

\author{
HAL Id: hal-02377702 \\ https://hal.science/hal-02377702
}

Submitted on 3 Dec 2020

HAL is a multi-disciplinary open access archive for the deposit and dissemination of scientific research documents, whether they are published or not. The documents may come from teaching and research institutions in France or abroad, or from public or private research centers.
L'archive ouverte pluridisciplinaire HAL, est destinée au dépôt et à la diffusion de documents scientifiques de niveau recherche, publiés ou non, émanant des établissements d'enseignement et de recherche français ou étrangers, des laboratoires publics ou privés. 
1 Estimation of Soil Evaporation and Vegetation Transpiration Using Two Trapezoidal

\section{Models from MODIS Data}

3 Yazhen Jiang ${ }^{1,2,3}$, Ronglin Tang ${ }^{1,2, ~ *}$, Xiaoguang Jiang ${ }^{2,4, *}$, Zhao-Liang $\mathrm{Li}^{1,5,3}$, Caixia Gao ${ }^{4}$

$4 \quad{ }^{1}$ State Key Laboratory of Resources and Environment Information System, Institute of Geographic

5 Sciences and Natural Resources Research, Chinese Academy of Sciences, Beijing 100101, China;

$6 \quad{ }^{2}$ University of Chinese Academy of Sciences, Beijing 100049, China;

$7 \quad{ }^{3}$ Icube (UMR7357), UdS, CNRS, 300 Bld Sébastien Brant, CS10413, Illkirch 67412, France;

$8 \quad{ }^{4}$ Key Laboratory of Quantitative Remote Sensing Information Technology, Academy of Opto-

9 Electronics, Chinese Academy of Sciences, Beijing 100094, China;

$10 \quad{ }^{5}$ Key Laboratory of Agri-informatics, Ministry of Agriculture/Institute of Agricultural Resources

11 and Regional Planning, Chinese Academy of Agricultural Sciences, Beijing 100081, China.

12 *Corresponding authors: Ronglin Tang (trl_wd@163.com); Xiaoguang Jiang (xgjiang@ucas.ac.cn)

13 Key Points:

- Soil evaporation and vegetation transpiration were estimated using two trapezoidal models.

- Land surface temperature of MODIS pixel was decomposed into soil and vegetation component temperatures.

17 - Analysis was made over three test sites. 


\section{Abstract}

Soil evaporation $\left(E T_{S}\right)$ and vegetation transpiration $\left(E T_{v}\right)$ are essential in evaporative demand analyses and agricultural applications. This study estimated $E T_{s}$ and $E T_{v}$ using two trapezoidal models, i.e. the conventional trapezoidal model and the end-member-based soil and vegetation energy partitioning (ESVEP) model, at three AmeriFlux tower sites. First, the land surface temperature (LST) of a Moderate Resolution Imaging Spectroradiometer (MODIS) pixel was decomposed into soil and vegetation temperatures ( $T_{s}$ and $T_{v}$, respectively) which involve important information related to $E T_{s}$ and $E T_{v}$ and were compared with corresponding temperatures from the Advanced Spaceborne Thermal Emission and Reflection Radiometer (ASTER). Then $E T_{s}$ and $E T_{v}$ were parameterized, and the total evapotranspiration (ET) was validated with the eddy covariance (EC) system measurements after energy imbalance corrections via the residual energy (RE) and Bowen ratio (BR) methods. The results showed that the ESVEP model partitioned $T_{s}$, with a root mean square error (RMSE) of 1.56-2.70 K (4.98-10.16\%), and $T_{v}$, with an RMSE of 2.54-2.80 K (9.73-11.11\%); indicating a higher accuracy than that from the conventional trapezoidal model, where the RMSE was 2.26-3.64 K (7.31-13.40\%) for $T_{s}$ separation and 2.82$4.62 \mathrm{~K}(9.80-15.49 \%)$ for $T_{v}$ separation. For the ET estimation, the ESVEP model still performed better. The estimation RMSE was 49.8-58.4 W/m² (22.8-27.2 \%) for the ESVEP model and 72.0$89.5 \mathrm{~W} / \mathrm{m}^{2}$ (29.8-41.1\%) for the conventional trapezoidal model, compared to the RE corrected measurements; the RMSE was 42.6-53.3 W/m² (24.4-28.1\%) for the ESVEP model and 57.5-78.1 $\mathrm{W} / \mathrm{m}^{2}$ (32.3-37.9\%) for the conventional trapezoidal model, compared to the BR corrected measurements.

\section{Introduction}

Evapotranspiration (ET, soil evaporation + vegetation transpiration) is a key component in the water cycle and energy exchange between the land surface and atmosphere, and it affects the availability of water and partition of turbulent energy fluxes on Earth's surface (Anderson et al., 2007; Li et al., 2009; Wang \& Dickinson, 2012; Long et al., 2012; Schlesinger \& Jasechko, 2014). Compared to the total $E T$, soil evaporation $\left(E T_{s}\right)$ may have more significant effects on crop/vegetation water use by decreasing the air vapor pressure deficit and reducing the overall evaporative demand, and vegetation transpiration $\left(E T_{v}\right)$ is more critical in agricultural applications for better allocating water resources and improving water use efficiency (Crow et al., 2008; Song et al., 2015; Tang \& Li 2017; Good et al., 2017). Remote sensing-based models play a dominant role in ET research and global implications (Tang et al., 2015a; Anderson et al., 2017; Zhang et al., 2017; Fisher et al.,2017), and the spatially distributed land surface temperature (LST) estimated from thermal infrared remote sensing data is widely used in the study of ET (Wang et al., 2006; Anderson et al., 2012).

$L S T$ /fraction vegetation cover $(F V C)$ feature model is one of widely used $E T$ estimation models, which is based on the interpretation of the contextual relationship between remotely sensed $L S T$ and FVC (Jiang \& Islam, 2003; Carlson, 2007; Zhang et al., 2016). At the first development of this method, if there exist a sufficient number of pixels representing a broad range of soil wetness and fractional vegetation cover in an image, and the outliers (e.g., clouds and sloped terrains) are removed, the envelope of these pixels could constitute a physically meaningful triangle or trapezoid. The vertices in the triangle or trapezoid are called dry or wet end-members with extreme temperatures which are related to extreme $E T_{s}$ or $E T_{v}$. 
To separate $E T_{s}$ and $E T_{v}$, two-source $L S T / F V C$ models have been put forward and developed. Nishida et al. (2003) proposed a two-source $L S T / F V C$ model in which the complementary relationship of the actual and potential $E T$ with a canopy conductance model was used to estimate $E T_{v}$, and the triangle space was used to estimate $E T_{s}$. By quasi-linear interpolation in the $L S T / F V C$ space, Zhang et al. (2008) developed a two-source energy separation algorithm to estimate the fraction of $E T_{s}$ and $E T_{v}$. Later, for avoiding the complex calculation of canopy conductance in the study of Nishida et al. (2003), Long and Singh (2012) developed a two-source LST/FVC trapezoidal model. For further enhancing of the parameterizations of $E T_{s}$ and $E T_{v}$, Yang et al. (2015) combined the conceptual trapezoidal space and the concept of the crop water stress index into the two-source $L S T / F V C$ model. Due to the fact that it is very subjective and prone to error and it requires the study areas to contain full vegetation and bare soil with extreme wet and dry conditions, two-source $L S T / F V C$ model usually theoretically calculates the boundaries from an energy balance equation of land surface and does not rely on the study area generating the $L S T / F V C$ spaces, allowing the determination of dry and wet end-members independently from the study area (Moran et al., 1994; Long and Singh, 2012, Sun et al, 2017).

With respect to these widely applied conventional trapezoidal models, there is a conventional interpretation that has been used in estimating $E T_{s}$ and $E T_{v}$. These trapezoidal models assume that the $T_{v}$ and $T_{s}$ vary simultaneously with the variation in soil moisture availability (Wang et al, 2010; Long \& Singh, 2012; Yang et al, 2015), and the $E T_{s}$ and $E T_{v}$ are estimated based on the assumption that they vary synchronously with the variation of $T_{s}$ and $T_{v}$ in the trapezoid, respectively (Sun, 2016). The decomposition method used to derive $E T_{s}$ and $E T_{v}$ in these conventional models would result that the soil evaporation fraction is approximately equal to the vegetation transpiration fraction (Tang \& Li, 2017). However, it has been reported that the $E T_{s}$ process primarily exploits water in the thin upper soil layer, whereas the $E T_{v}$ process usually uses water from the deep root zone layer. It means that there should exist a difference in the speed of the variation between $E T_{v}$ and $E T_{s}$ because vegetation can absorb deep layer soil moisture to maintain transpiration, while the surface soil dries out. Therefore, the response of the soil water content to $E T_{s}$ should be different from that to $E T_{v}$ (Carlson et al., 2013), and the assumption that $E T_{s}$ and $E T_{v}$ vary simultaneously in conventional trapezoidal models may be not always appropriate (Sun 2016; Tang \& Li, 2015b, 2017).

To consider different responses of the soil water content in the upper surface layer to $E T_{s}$ and in the deeper root zone layer to $E T_{v}$, Tang \& $\mathrm{Li}(2015 \mathrm{~b}, 2017)$ developed another trapezoidal model, an end-member-based soil and vegetation energy partitioning model (i.e., the ESVEP model). The ESVEP model separates $E T_{s}$ and $E T_{v}$ based on two-phase $E T$ dynamics with the variations in soil moisture in different layers. First, with the decrease in the soil water content in the upper soil layer from sufficiency to zero, $E T_{s}$ varies from the maximum to zero, but $E T_{v}$ keeps potential due to the soil water content in the deep root zone remaining sufficient. Second, when the soil moisture availability in the root zone gradually decreases from sufficiency to the threshold value for the wilting point, $E T_{v}$ varies from the potential value to zero due to the fact that vegetation is waterstressed, and $E T_{s}$ remains at zero because the soil water content in the upper soil layer remains at zero. With the similar interpolation process of ET estimation, Sun (2016) also indicated that $T_{v}$ should vary after $T_{s}$ because vegetation can absorb soil moisture in deep layer to maintain transpiration, and a two-stage trapezoid is suggested to estimate soil evaporation fraction and vegetation transpiration fraction. 
It is clear that the conventional trapezoidal model and the ESVEP model developed by Tang \& Li (2015b, 2017) have different interpretation processes in terms of separating $E T_{s}$ and $E T_{v}$. Two interpretation processes related to different trapezoidal models may result in totally different results and it is necessary to evaluate the differences from them. In addition, how the temperatures of the dry and wet end-members are determined also differs in the conventional trapezoidal model and the ESVEP model. The surface temperatures of the dry and wet end-members in the conventional trapezoidal models are usually determined either semi-empirically from the scatterplot of the LST/FVC model (Tang et al., 2010) or theoretically using the surface energy balance theory (Long \& Singh, 2012; Sun et al., 2016). Specially, three main theoretical methods for determining dry and wet edges of the LST/FVC spaces were discussed in Sun et al (2017). Some models also used the near-surface air temperature as the temperature of the wet end-members (Long \& Singh, 2012). Whereas in the ESVEP model, the net radiation was first diverged into soil and vegetation components by considering the transmission of direct and diffuse shortwave radiation separately from the transmission of longwave radiation through the canopy, then, the temperature of four end-members were calculated with the separated soil and vegetation net radiations.

Therefore, the objective of this study is to estimate $E T_{s}$ and $E T_{v}$ using the ESVEP model and the conventional trapezoidal model at three AmeriFlux tower sites with different climate types in the USA, to investigate a two-source model with better performance based on the same remote sensing data inputs. To focus on two different interpretation processes related to the two trapezoidal models and simplify the analysis, only the different processes for separating $\mathrm{ET}_{\mathrm{s}}$ and $\mathrm{ET}_{\mathrm{v}}$ are investigated, and the end-members are determined by the same method that the ESVEP model used. For the conventional trapezoidal model, the near-surface air temperature is also regarded as the temperature of the wet end-members, which is discussed as another situation of this model. The present study is organized as follows; Section 2 presents the methods of this study and Section 3 gives the introduction of test sites and materials. The results and discussion are shown in Section 4 , and the conclusions are provided in Section 5.

\section{Materials and Methods}

\subsection{The conventional two-source trapezoidal model}

The conventional two-source trapezoidal model is based on the interpretation of the LST/FVC space. Figure 1(a) illustrates the LST/FVC space and concepts of the isopleths for soil surface moisture. Theoretically, there are four critical points (i.e., end-members) within the trapezoidal framework: A, B, C, and D, or trapezoid ABCD. Point A $\left(F V C=0, L S T=T_{s, d}\right)$ represents the driest bare surface with the highest soil temperature $\left(T_{s, d}\right)$; point $\mathrm{B}\left(F V C=0, L S T=T_{s, w}\right)$ represents the wettest bare surface with the lowest soil temperature $\left(T_{s, w}\right)$; point $\mathrm{C}\left(F V C=1, L S T=T_{v, w}\right)$ indicates the fully vegetated surface with the lowest vegetation temperature $\left(T_{v, w}\right)$; point $\mathrm{D}(F V C=1$, $\left.L S T=T_{v, d}\right)$ indicates the fully vegetated surface with the highest vegetation temperature $\left(T_{v, d}\right)$. The line $\mathrm{AD}$ is the so called dry edge, which represents surfaces with the largest amount of water stress for the full range of the $F V C$, and the $E T$ of these surfaces is equal to zero. Analogously, the line $\mathrm{BC}$ is the wet edge, which represents wet surfaces at equilibrium $E T$ rates $\left(E T_{s, w}\right.$ and $\left.E T_{v, w}\right)$ without water stress. The dry and wet edges constitute the boundary conditions of the trapezoidal model (Allen et al., 2007). 
The conventional trapezoidal model for $E T$ estimation virtually is an interpolating scheme between the potential $E T$ at the wet edge and the minimum ET at the dry edge. To prepare for the interpolation, the corresponding temperatures of the dry $\left(T_{s_{-} d r y}\right)$ and wet $\left(T_{s_{-} w e t}\right)$ edges of a give point $\mathrm{P}(L S T, F V C)$ are calculated first:

$T_{s \_d r y}=T_{s, d}+F V C *\left(T_{v, d}-T_{s, d}\right)$

$T_{s_{-} \text {wet }}=T_{s, w}+F V C^{*}\left(T_{v, w}-T_{s, w}\right)$

The composite $L S T$ is decomposed to the soil and vegetation component temperatures ( $T_{s}$ and $T_{v}$, respectively) by interpolating the temperatures from four critical points:

$T_{s}=T_{s, w}+\left(L S T-T_{s_{-} \text {wet }}\right) /\left(T_{s_{-} d r y}-T_{s_{-} \text {wet }}\right) *\left(T_{s, \mathrm{~d}}-T_{s, w}\right)$

$T_{v}=T_{v, w}+\left(L S T-T_{s_{-} \text {wet }}\right) /\left(T_{s_{-} d r y}-T_{s_{-} w e t}\right) *\left(T_{v, d}-T_{v, w}\right)$

Then, $E T_{s}$ and $E T_{v}$ are parameterized as follows:

$E T_{s}=\left(\left(T_{s, d}-L S T\right) /\left(T_{s, d}-T_{s, w}\right)\right) E T_{s, w}$

$E T_{v}=\left(\left(T_{v, d}-L S T\right) /\left(T_{v, d}-T_{v, w}\right)\right) * E T_{v, w}$

$E T_{s, w}$ and $E T_{v, w}$ represent the equilibrium $E T$ rates for soil and vegetation without water stress, respectively.

The total ET is the sum of $\mathrm{ET}_{\mathrm{s}}$ and $\mathrm{ET}_{\mathrm{v}}$ :

$E T=\left(\left(T_{s, d}-L S T\right) /\left(T_{s, d}-T_{s, w}\right)\right) * E T_{s, w}+\left(\left(T_{v, d}-L S T\right) /\left(T_{v, d}-T_{v, w}\right)\right) * E T_{v, w}$

For the conventional trapezoidal model, the near-surface air temperature is sometimes treated as an alternative for the temperature of the wet edge, which is analyzed as another situation for this model in this study; namely,

$E T_{-} T_{a}=\left(\left(T_{s, d}-L S T\right) /\left(T_{s, d}-T_{a}\right)\right) * E T_{s, w}+\left(\left(T_{v, d}-L S T\right) /\left(T_{v, d}-T_{a}\right)\right) * E T_{v, w}$

where $E T_{-} T_{a}$ represents the total $E T$, where the near-surface air temperature is treated as the temperature of the wet edge.

Figure 1. Schematic diagrams of (a) the conventional two-source trapezoidal model based on the LST/FVC space and (b) the ESVEP model

2.2 The end-member-based soil and vegetation energy partitioning model (ESVEP model)

The ESVEP model can be regarded as another conventional two-source $L S T / F V C$ trapezoidal model that is composed of two triangles (triangle 1 and triangle 2), as shown in Figure 1 (b). However, in the ESVEP model (Tang \& Li, 2015b; 2017), the $E T_{s}$ and $E T_{v}$ vary differently rather than simultaneously. The two triangles in this model are related to the two stages of ET estimation, where stage 1 corresponds to the lower triangle and stage 2 corresponds to the upper triangle. In stage 1, for a given $F V C$, with the decrease of the soil water content in the upper soil layer from sufficiency in the wet edge to zero in dry edge I, the $E T_{s}$ varies from a maximum to zero. Dry edge I represents the case of dry soil in the upper layer, with sufficient water content in the root zone 
and $E T_{v}$ keeps potential value. In stage 2, with the soil moisture availability in the root zone gradually decreasing from 1 to the threshold value of the wilting point, the $E T_{v}$ varies from the potential value to zero. Dry edge II represents the same case as the dry edge in the conventional trapezoidal model, including surfaces with the largest water stress.

In theory, a given pixel can be located in either triangle 1 (e.g., Q1 ( $L S T, F V C)$ ) or triangle 2 (e.g., Q2 $(L S T, F V C))$. A critical surface temperature $\left(T^{*}\right)$ is used to identify which triangle the point is in (Tang \& Li, 2017):

$T^{*}=\left[\left(T_{s, w}^{4}(1-F V C)+F V C^{*} T_{v, w}^{4}\right)\right]^{1 / 4}$

If the given pixel is found in triangle $1\left(L S T \leqslant T^{*}\right)$, the $T_{s}$ and $T_{v}$ can be estimated as:

$T_{v}=T_{v, w}$

$T_{s}=\left[\left(L S T_{R}^{4}-F V C^{*} T_{v}^{4}\right) /(1-F V C)\right]^{1 / 4}$

In this case, the $E T_{v}$ is close to the potential value and the $E T_{s}$ varies from a maximum to zero. The $E T_{s}$ and $E T_{v}$ can be derived as follows:

$E T_{s}=\frac{T_{s, d}-T_{s}}{T_{s, d}-T_{s, w}} E T_{s, w}$

$E T_{v}=E T_{v, \mathrm{w}}$

Similarly, if the pixel is located in triangle 2 ( $\mathrm{LST}>\mathrm{T}^{*}$ ), the $T_{s}$ and $T_{v}$ can be separated as follows:

$T_{s}=T_{s, d}$

$T_{v}=\left\{\left[\mathrm{LST}^{4}-(1-F V C) T_{s}^{4}\right] / F V C\right\}^{1 / 4}$

In this situation, the $E T_{s}$ should be close to zero and the $E T_{v}$ varies from the potential value to zero. The $E T_{s}$ and $E T_{v}$ can be calculated as

$E T_{s}=0$

$E T_{v}=\frac{T_{v, d}-T_{v}}{T_{v, d}-T_{v, w}} E T_{v, w}$

where $T_{s, d}, T_{s, w}, T_{v, d}$ and $T_{s, d}$ represent the temperatures of the four end-members, which have same meanings as those in the conventional trapezoidal model. $E T_{s, w}$ and $E T_{v, w}$ represent the same variables as those in the conventional trapezoidal model, which are the maximum ET values for soil and vegetation during a situation without water stress, respectively.

2.3 Divergence of surface net radiation and soil heat flux

As stated above, to focus on different interpretation processes in the two trapezoidal models and simplify the analysis, the temperatures of the four end-members are calculated using the same method as that in the ESVEP model, in which the net radiations of the soil and vegetation components ( $R_{n, s}$ and $R_{n, v}$, respectively) are separated at first. The divergence of surface net radiation was conducted with an algorithm which is applied by Kustas \& Norman (2000) to replace the exponential extinction of net radiation (i.e., Beer's Law) that is originally used in the twosource N95 model. In detail, the $R_{n, s}$ and $R_{n, v}$ are separated by considering the transmission of direct 
and diffuse shortwave radiation separately from the transmission of longwave radiation through the canopy (Norman \& Kustas, 1998; Tang \& Li, 2017):

$$
\begin{aligned}
& R_{n, \mathrm{v}}=\left(1-\tau_{s w}\right)\left(1-\alpha_{\mathrm{v}}\right) R_{g}+\left[1-\exp \left(-k_{L} L A I\right)\right]\left(L_{s k y}+L_{s}-2 L_{\mathrm{v}}\right) \\
& R_{n, s}=\tau_{s w}\left(1-\alpha_{s}\right) R_{g}+\exp \left(-k_{L} L A I\right) L_{s k y}+\left[1-\exp \left(-k_{L} L A I\right)\right] L_{\mathrm{v}}-L_{s}
\end{aligned}
$$

where $\tau_{s w}$ represents the canopy transmittance for shortwave radiation; $\alpha_{\mathrm{v}}$ and $\alpha_{\mathrm{s}}$ represent soil and vegetation albedo, respectively; $R_{g}$ represents solar radiation $\left(\mathrm{W} / \mathrm{m}^{2}\right) ; L_{s k y}, L_{v}$, and $L_{s}$ represent longwave emissions from the sky, vegetation, and soil, respectively; and $\mathrm{k}_{\mathrm{L}}$ represents the extinction coefficient, which is approximately 0.95 .

The soil heat flux $\left(G, \mathrm{~W} / \mathrm{m}^{2}\right)$ is estimated following the work of Tang and $\mathrm{Li}(2017)$ :

$$
G=\Gamma^{*} R_{n, s}
$$

where $\Gamma$ represents the fraction of the soil heat flux to soil net radiation and is equal to 0.296 in this study.

\subsection{Estimation of the temperatures of the end-members}

Then the temperatures of the four end-members in the two trapezoidal models are calculated using an adapted method that proposed by Moran et al. (1994) and applied in the study of Tang and Li (2017), according to the surface energy balance theory and Penman-Monteith equation (Moran et al., 1994):

$$
T_{s d}=\frac{r_{a s}\left(R_{n, s}-G_{s}\right)}{\rho C_{p}}+T_{a}
$$

$T_{v d}=\frac{r_{a v} R_{n, v}}{\rho C_{p}} \frac{\gamma\left(1+r_{v d} / r_{a v}\right)}{\Delta+\gamma\left(1+r_{v d} / r_{a v}\right)}-\frac{V P D}{\Delta+\gamma\left(1+r_{v d} / r_{a v}\right)}+T_{a}$

$T_{s w}=\frac{r_{a s}\left(R_{n, s}-G_{s}\right)}{\rho C_{p}} \frac{\gamma}{\Delta+\gamma}-\frac{V P D}{\Delta+\gamma}+T_{a}$

$T_{v w}=\frac{r_{a v} R_{n, v}}{\rho C_{p}} \frac{\gamma\left(1+r_{v w} / r_{a v}\right)}{\Delta+\gamma\left(1+r_{v w} / r_{a v}\right)}-\frac{V P D}{\Delta+\gamma\left(1+r_{v w} / r_{a v}\right)}+T_{a}$

where $T_{a}$ represents air temperature $(\mathrm{K}) ; \rho$ is the density of air $\left(\mathrm{kg} / \mathrm{m}^{3}\right) ; C_{P}$ represents the volumetric heat capacity of air $\left(\mathrm{J} /\left({ }^{\circ} \mathrm{Cm}^{3}\right)\right) ; \gamma$ represents the psychrometric constant $\left(\mathrm{kPa} /{ }^{\circ} \mathrm{C}\right) ; \Delta$ represents the slope of saturated vapor pressure versus air temperature $\left(\mathrm{kPa} /{ }^{\circ} \mathrm{C}\right) ; V P D$ represents the vapor pressure deficit of air $(\mathrm{kPa}) ; r_{v d}$ represents the canopy resistance of nearly closed stomata (set as 2,000 s/m), and $r_{v w}$ represents the canopy resistance under well-watered condition and is estimated to be 100/LAI (Liang et al.,1994, Allen et al.,1998). $r_{a}$ represents the aerodynamic resistance and can be calculated as

$$
r_{a v}\left(\text { or } r_{a s}\right)=\frac{\left[\ln \left(\frac{z_{u}-d}{z_{o m}}\right)-\psi_{m}\right]\left[\ln \left(\frac{z_{t}-d}{z_{o h}}\right)-\psi_{h}\right]}{k^{2} u}
$$


where $z_{u}$ and $z_{t}$ represent the heights of the wind speed and $\mathrm{T}_{\mathrm{a}}$ measurements $(\mathrm{m})$, respectively; $\mathrm{k}$ represents the von Karman's constant; u represents the wind speed (m); $\Psi_{\mathrm{m}}$ and $\Psi_{\mathrm{h}}$ represent the stability correction functions for momentum and heat transfer, respectively; $d$ represents the zero plane displacement height $(\mathrm{m})$; $z_{\text {oh }}$ represents the roughness height for the surface heat transfer $(\mathrm{m})$; and $z_{o m}$ represents the surface momentum roughness height $(\mathrm{m})$ (Norman et al, 1995).

After the calculation of the related parameters, the potential soil evaporation $\left(E T_{s, w}\right)$ and vegetation transpiration $\left(E T_{v, w}\right)$ mentioned in the two trapezoidal models are estimated using the following equations:

$E T_{s, w}=\frac{\Delta \times\left(R_{n, s}-G_{s}\right)+\rho C_{p} V P D / r_{a s}}{\Delta+\gamma}$

$E T_{v, w}=\frac{\Delta \times R_{n, v}+\rho C_{p} V P D / r_{a v}}{\Delta+\gamma\left(1+r_{v w} / r_{a v}\right)}$

\section{Test sites and datasets}

\subsection{Test sites and flux data}

This study is conducted at three AmeriFlux tower sites named US-Bol (in Illinois state), US-ARM (in Oklahoma state), and US-Aud (in Arizona state). These three sites are evenly distributed from east to west across the contiguous USA, as shown in Figure 2. The vegetation types around these sites are crops and grass, and the climates are classified as humid continental (warm summers), mid-latitude desert, and humid subtropical, respectively, which are the three main climate types in the USA. The mean annual precipitation at these sites ranges from $368 \mathrm{~mm} /$ year to $727 \mathrm{~mm} /$ year, and the mean annual temperature ranges from $11.55^{\circ} \mathrm{C}$ to $16.08{ }^{\circ} \mathrm{C}$. The details on these flux sites are listed in Table 1.

Figure 2.The location of the test sites (the map is from ESRI)

The AmeriFlux tower datasets are available every $30 \mathrm{~min}$, and the datasets for the measured meteorological data and surface flux data at these three test sites are downloaded from the AmeriFlux File Transfer Protocol servers (http://ameriflux.lbl.gov/). The datasets have been standardized and passed quality assurance and quality control (QA/QC) checks (Di et al., 2015). The meteorological variables used in this study include wind speed, relative humidity, air temperature, and atmospheric pressure. The flux data include latent heat flux $(L E)$ and sensible heat flux $(H)$, which are measured regularly by an eddy covariance (EC) system. A series of data quality control steps have been conducted to obtain reliable EC-measured $L E$ and $H$ (remove the data larger than $700 \mathrm{~W} / \mathrm{m}^{2}$ or less than $-100 \mathrm{~W} / \mathrm{m}^{2}$ ) (Tang et al., 2013; Di et al., 2015). Downward/upward shortwave and longwave radiations and the soil heat flux $(G)$ are also collected.

The EC-measured surface energy components ( $L E$ and $H$ ) are subject to errors in the energy budget closure (i.e., $R_{n^{-}} G>L E+H$ ) (Stoy et al., 2013) which are mainly from the measurement error, the length of the sampling intervals, the dispersive fluxes not being sampled by the EC system. For effective validation of the results, the residual energy (RE) and Bowen ratio (BR) correction methods have been widely applied in a number of papers to validate the $L E$ and $H$ from diverse ET models (Anderson et al., 2008; Sánchez et al., 2008). In the RE correction method, the imbalanced energy is completely included in the LE (Twine et al., 2000). In the BR method, the 
surface available energy is repartitioned into $H$ and $L E$ by conserving the original Bowen ratio measured by the EC system. The two correction methods are also used in this study to correct the energy imbalance in the surface energy measurements, and the corrected $L E$ corresponding to the satellite overpass time is used to validate the estimated $E T$ from the two trapezoidal models.

Table 1.The information of test sites on location, vegetation, and climate

\begin{tabular}{|c|c|c|c|c|c|c|c|c|}
\hline Site name & State & $\begin{array}{l}\text { Elevation } \\
\text { (m) }\end{array}$ & $\begin{array}{l}\text { Latitude } \\
\left({ }^{\circ} \mathrm{N}\right)\end{array}$ & $\begin{array}{l}\text { Longitude } \\
\left(^{\circ}\right)\end{array}$ & $\begin{array}{l}\text { Veget } \\
\text { ation }\end{array}$ & Climate & $\begin{array}{l}\text { Mean annual } \\
\text { precipitation } \\
(\mathrm{mm})\end{array}$ & $\begin{array}{c}\text { Mean annual } \\
\text { temperature } \\
\left({ }^{\circ} \mathrm{C}\right)\end{array}$ \\
\hline US-Bo1 & Illinois & 219 & 40.0062 & -88.2904 & Crop & $\begin{array}{c}\text { Humid } \\
\text { continental }\end{array}$ & 724 & 11.55 \\
\hline US-ARM & Oklahoma & 129 & 36.6058 & -97.4884 & Crop & Mediterranean & 504 & 16.08 \\
\hline US-Aud & Arizona & 1469 & 31.5907 & -110.5092 & Grass & $\begin{array}{l}\text { Mid-latitude } \\
\text { desert }\end{array}$ & 368 & 15.82 \\
\hline
\end{tabular}

\subsection{MODIS data}

The MODIS products used in this study include the calibrated radiance product (MOD021KM), LST and emissivity product (MOD11_L2), surface reflectance product (MOD09GA), geolocation product (MOD03), leaf area index product (MOD15A2) and cloud mask product (MOD35_L2). The MOD021KM product consists of calibrated and geolocated radiances and reflectance at the top of the atmosphere (TOA) in 36 bands, to be used for the estimation of the net radiation. The level 2 MOD11_L2 product is generated daily using the generalized split window algorithm (Wan \& Dozier, 1996), with a $1 \mathrm{~km}$ spatial resolution, to provide the surface temperature. The MOD03 product outputs a dataset that mainly includes geodetic coordinates (latitude and longitude), solar zenith and azimuth angles, satellite zenith and azimuth angles, and ground elevation in each $1 \mathrm{~km}$ pixel for the geo-calibration of the MOD11_L2 product. The surface spectral reflectance for bands 1-7, with a spatial resolution of 500 m extracted from MOD09GA, is first resampled to $1 \mathrm{~km}$ with a bilinear resampling method, which is then used to estimate the albedo. The leaf area index is extracted from the MOD15A2 product to estimate the canopy resistance and separate the soil and vegetation net radiations. The MOD35 product is used to guarantee the clear-sky selections in which only the days with highest quality (the quality assurance flag is "11") are selected.

\subsection{ASTER data}

The ASTER data used in this study include the surface kinetic temperature (AST_08) and ASTER surface reflectance VNIR and SWIR (AST_07) data products. AST_08 is a product generated using the five thermal infrared (TIR) bands between the 8 and $12 \mu \mathrm{m}$ spectral ranges, and this product contains surface temperatures at a $90 \mathrm{~m}$ spatial resolution for land areas only. The AST_07 data product contains measures of reflectance in both the visible and near infrared (VNIR) and shortwave infrared (SWIR) bands. The data from AST_07 are resampled to $90 \mathrm{~m}$ from $15 \mathrm{~m}$ with a bilinear resampling method in this study.

This study compares $T_{s}$ and $T_{v}$ separated from the LST of a MODIS pixel with corresponding temperatures from ASTER. In detail, A MODIS mixed temperature pixel, with a $1 \mathrm{~km}$ spatial resolution, corresponds to $11 * 11$ pixels from AST_08. These corresponding AST_08 pixels are soil or vegetation pixels, and the average temperatures of each category are used to validate the $T_{s}$ or $T_{v}$ separated from a MODIS temperature pixel. The identification of the soil or vegetation category of an AST_08 pixel is conducted according to the FVC of the pixel. Specifically, when 
the $F V C$ is larger than 0.8 , the related pixel is identified as vegetation; when the $F V C$ is smaller than 0.2, the related pixel is identified as soil (Song et al., 2015). The $F V C$ is calculated from normalized difference vegetation index $(N D V I)$ values, which are estimated from the surface reflectance with AST_07 bands 2 and 3. The value of the FVC is calculated from the following equation (Gebremichael et al., 2009):

$$
F V C=\left(\frac{N D V I-N D V I_{\text {min }}}{N D V I_{\text {max }}-N D V I_{\text {min }}}\right)^{2}
$$

where $N D V I_{\min }$ represents the minimum value of the $N D V I$ and $N D V I_{\max }$ represents the maximum value of the NDVI.

The flowchart for the estimation and validation of $T_{s}, T_{v}, E T_{s}$ and $E T_{v}$ with meteorological data, MODIS data and ASTER data are displayed in Figure 3. And the spatial and temporal resolutions of different ASTER and MODIS data products used in this study are shown in Table 2.

Figure 3. Flowchart of the estimation and validation of soil temperature $\left(T_{s}\right)$, vegetation temperature $\left(T_{v}\right)$, soil evaporation $\left(E T_{s}\right)$ and vegetation transpiration $\left(E T_{v}\right)$

Table 2. The spatial and temporal resolutions of different ASTER and MODIS data products used in this study

\begin{tabular}{|c|c|c|c|c|}
\hline Sensor & Product & Description & $\begin{array}{l}\text { Spatial } \\
\text { resolutio } \\
\mathbf{n}\end{array}$ & $\begin{array}{l}\text { Temporal } \\
\text { resolution }\end{array}$ \\
\hline \multirow{6}{*}{$\begin{array}{l}\text { MODI } \\
\mathbf{S}\end{array}$} & MOD021KM & Calibrated radiance product & $1000 \mathrm{~m}$ & Daily \\
\hline & MOD11_L2 & LST and emissivity product & $1000 \mathrm{~m}$ & Daily \\
\hline & MOD03 & Geolocation product & $1000 \mathrm{~m}$ & Daily \\
\hline & MOD35_L2 & Cloud mask product & $1000 \mathrm{~m}$ & Daily \\
\hline & MOD09GA & Surface reflectance product & $500 \mathrm{~m}$ & Daily \\
\hline & MOD15A2 & Leaf area index product & $500 \mathrm{~m}$ & 8-day \\
\hline \multirow[t]{2}{*}{$\begin{array}{l}\text { ASTE } \\
\quad \text { R }\end{array}$} & AST_07 & Surface reflectance product & $30 \mathrm{~m}$ & $\begin{array}{l}\text { Daily (but may not } \\
\text { cover the study } \\
\text { area) }\end{array}$ \\
\hline & AST_08 & $\begin{array}{c}\text { Surface kinetic temperature } \\
\text { product }\end{array}$ & $90 \mathrm{~m}$ & $\begin{array}{l}\text { Daily (but may not } \\
\text { cover the study } \\
\text { area) }\end{array}$ \\
\hline
\end{tabular}

Although the ASTER standard products for LST and emissivity have been widely used, significant uncertainty in the temperature and emissivity algorithm often occur (Jiménez-Muñoz et al., 2006), which could introduce relatively large errors in LST estimation. Therefore, the data are removed when a large difference ( $5 \mathrm{~K}$ ) between the MODIS mixed pixel $L S T$ and the corresponding ASTER averaged LST occurs in this paper. Finally, by combining the gaps in the MODIS data, ASTER data, meteorological data and ET data, a total number of 26 days, 15 days and 17 days at the three test sites are selected, as shown in Table 3.

Table 3.Selected days at the three test flux sites 


\begin{tabular}{cl}
\hline Site & \multicolumn{1}{c}{ Selected days } \\
\hline US-Bo1 & 2001238; 2001270; 2001302; 2001318; 2002001; 2002033; 2003068; 2003285;2003292; \\
N=26 & 2003324; 2003333; 2004071; 2004208; 2004263; 2004304; 2005018; 2005105; 2005114; \\
& $2005210 ; 2005322 ; 2006069 ; 2006076 ; 2006124 ; 2006197 ; 2006204 ; 2006213$ \\
US-ARM & $2010058 ; 2010131 ; 2010202 ; 2010234 ; 2011004 ; 2011013 ; 2011044 ; 2011070 ; 2011124 ;$ \\
N=15 & $2011132 ; 2011173 ; 2011214 ; 2011221 ; 2011262 ; 2011294$ \\
& \\
US-Aud & $2007051 ; 2007074 ; 2007083 ; 2007090 ; 2007099 ; 2007147 ; 2007282 ; 2008109 ; 2009015 ;$ \\
N=17 & $2009031 ; 2009088 ; 2009191 ; 2009271 ; 2009319 ; 2010098 ; 2010107 ; 2010322$ \\
\hline
\end{tabular}

\section{Results and Discussion}

4.1 Validation of net radiation with measured data

In these two trapezoidal models, the $R_{n, s}$ and $R_{n, v}$ determine the surface temperature estimation of the four end-members and influence the accuracy in the estimations of $E T_{s}$ and $E T_{v}$. Figure 4 shows the comparison of estimated net radiation $\left(R_{n}\right)$ and the corresponding ground-based measurements at these three flux sites. The $R_{n}$ has a wide range of variations between $269.8 \mathrm{~W} / \mathrm{m}^{2}$ and 697.5 $\mathrm{W} / \mathrm{m}^{2}$ for the model estimates and between $254.3 \mathrm{~W} / \mathrm{m}^{2}$ and $698.1 \mathrm{~W} / \mathrm{m}^{2}$ for the ground-based measurements at the three flux sites. It is clear that, overall, the model-estimated $R_{n}$ agrees well with the ground-based measurement, with a small bias of $-10.5 \mathrm{~W} / \mathrm{m}^{2}$ and an RMSE of $37.7 \mathrm{~W} / \mathrm{m}^{2}$ at the US_Bo1 site, a bias of $-3.4 \mathrm{~W} / \mathrm{m}^{2}$ and an RMSE of $42.4 \mathrm{~W} / \mathrm{m}^{2}$ at the US_ARM site, and a bias of $-8.7 \mathrm{~W} / \mathrm{m}^{2}$ and an RMSE of $39.1 \mathrm{~W} / \mathrm{m}^{2}$ at the US_Aud site, respectively. This good performance provides the reliability of determining the dry/wet end-members and, subsequently, the retrieval of $E T_{s}$ and $E T_{\nu}$.

Figure 4.Comparison of estimated $R_{n}$ and ground-based measurements at three flux sites

\subsection{Estimations of the surface temperatures of the end-members}

The accurate estimation of the surface temperatures of the four end-members is significant for the separation of the $T_{s}$ and $T_{v}$ and the subsequent parameterization of $E T_{s}$ and $E T_{v}$. Figure 5 shows the surface temperatures of four end-members estimated using Eqs.(13a-13d), together with the MODIS LST and near-surface air temperature measurements at three flux sites. In the figure, $T s \_d s$ and $T s \_d v$ represent the surface temperature estimated in dry soil and dry vegetation, respectively; similarly, $T s_{-} w s$ and $T s_{-} w v$ represent the surface temperature estimated in wet soil and wet vegetation, respectively, and $T s_{-} r s$ and $T a$ represent the MODIS $L S T$ and near-surface air temperature measurements, respectively.

Overall, the temporal variations in $T s \_d s, T s \_d v, T s \_w s, T s \_w v$ and the MODIS $L S T$ have similar trends to that in $T a$, and these variations vary considerably over the course of the season due to seasonally different radiations and atmospheric conditions. At all three flux sites, the surface temperature estimated in the dry soil is the highest, followed by the surface temperature of the dry vegetation, as all available energies during these two conditions are partitioned into sensible heat flux for heating the near-surface air (Tang \& Li, 2017). The surface temperature estimated in the wet soil is slightly higher or lower than that in the wet vegetation. The MODIS LST on different days fell between the maximum and minimum temperatures of the four end-members. The near- 
surface air temperature is larger than the surface temperature estimated in the wet end-members on most days, especially at the US_ARM site and US_Aud site. At the US_Bo1 sites, they are similar on most days. The differences may result from the different vegetation types at different flux sites which, in turn, lead to variations in the photosynthesis, water use and fraction of incoming solar radiation and the interaction between air and surfaces.

Figure 5.Temporal variations in the surface temperature estimated in the dry soil ( $\left.T s_{-} d s\right)$, dry vegetation $\left(T s \_d v\right)$, wet soil $\left(T s \_w s\right)$, wet vegetation $\left(T s \_w v\right)$, MODIS LST $\left(T s \_r s\right)$ and nearsurface air temperature ( $T a$ ) at the (a)US_Bo1, (b) US_ARM and (c) US_Aud sites.

\subsection{Comparison of component temperatures from two trapezoidal models and those from ASTER}

The $T_{s}$ and $T_{v}$ are compared with the corresponding temperatures from ASTER in this study. To validate the accuracy of the LST from the ASTER data (AST_08), temperature calculated from the upwelling longwave radiation measured at the three flux towers is used as true temperature value, because that the site temperature measurement has limited spatial representation (Li et al., 2013). A comparison between the $L S T$ from ASTER and the computed $L S T$ from the radiation measurements is displayed in Figure 6. The results indicate that the ASTER LST is in acceptable agreement with that from the ground observations, with biases of $0.81 \mathrm{~K}, 1.38 \mathrm{~K}$ and $0.58 \mathrm{~K}$ and RMSEs of $2.33 \mathrm{~K}, 2.14 \mathrm{~K}$ and $2.16 \mathrm{~K}$ at the US_Bo1 site, US_ARM site and US_Aud site, respectively. The accuracy related to the ASTER $L S T$ demonstrated at these three sites is similar to that $(2.25 \mathrm{~K})$ from a previous study (Song et al., 2015). The differences between the ASTER $L S T$ and that from the measurements are mainly from uncertainties or errors in the sensor calibration, assumed emissivity, and spatial heterogeneity. The comparable accuracy of the ASTER LST makes it possible and credible to validate the $T_{S}$ and $T_{v}$ separated from the two trapezoidal models.

Figure 6.Comparison of $L S T$ from ASTER and that computed from radiation measurements

The two-dimensional plots of the separated $T_{s}$ and $T_{v}$ and those from ASTER at three test sites are demonstrated in Figure 7. In the plots, $T_{s}$ separations are shown in Figure 7 (a) (c) (e), and $T_{v}$ separations are shown in Figure 7 (b) (d) (f). The statistical bias, RMSE and the relative RMSE (RMSE value presented as percentage of mean temperature value $\left({ }^{\circ} \mathrm{C}\right)$ ) are displayed in Table 4.

Regarding to the $T_{s}$ separations, the ESVEP model performs better than the conventional model. Specially, the biases related to the ESVEP model are $0.19 \mathrm{~K},-0.10 \mathrm{~K}$, and $0.42 \mathrm{~K}$ at the US_Bo1 site, US_ARM site and US_Aud site, respectively, and the RMSEs are $2.76 \mathrm{~K}(10.16 \%), 2.04 \mathrm{~K}$ $(7.46 \%)$, and $1.56 \mathrm{~K}(4.98 \%)$, respectively. When referring to the conventional trapezoidal model, the biases are $-1.86 \mathrm{~K}, 0.29 \mathrm{~K}$, and $0.61 \mathrm{~K}$ at the US_Bo1 site, US_ARM site and US_Aud site, respectively, and the RMSEs are $3.64 \mathrm{~K}(13.40 \%), 2.37 \mathrm{~K}(8.66 \%)$, and $2.29 \mathrm{~K}(7.31 \%)$, respectively. For the $T_{v}$ separations, the negative biases at all three sites revealed underestimations of the $T_{v}$ from both two models. Specifically, the biases related to the ESVEP model are $-0.83 \mathrm{~K}$, $-1.63 \mathrm{~K}$, and $-1.71 \mathrm{~K}$ and related to the conventional trapezoidal model are $-0.91 \mathrm{~K},-0.54 \mathrm{~K}$, and $3.09 \mathrm{~K}$, respectively. The ESVEP model performs similar with the conventional model at the US_Bo1 site, where the RMSE is $2.80 \mathrm{~K}(9.73 \%)$ for the ESVEP model and is $2.82 \mathrm{~K}(9.80 \%)$ for the conventional trapezoidal model. At other two sites, the ESVEP model performed better. At the US_ARM site, the RMSE for the ESVEP model is $2.54 \mathrm{~K}(10.17 \%)$ and for the conventional trapezoidal model is $3.51 \mathrm{~K}(14.06 \%)$. At the US_Aud site, the RMSE of the ESVEP model is 
$2.80 \mathrm{~K}(11.11 \%)$ and the RMSE of the conventional trapezoidal model is $4.62 \mathrm{~K}(15.49 \%)$. As for different sites which have different climates, the two trapezoidal models separate $T_{s}$ with high accuracy at the US_Aud site which has mid-latitude desert climate, and separate $T_{v}$ with high accuracy at the US_Bo1 site which has humid continental climate. This reason for this difference is that high humidity generates high $F V C$ which leads to better $T_{v}$ separation, vice versa. And the different $T_{s}$ and $T_{v}$ separations at the same site further reveals that the assumption that $T_{s}$ and $T_{v}$ vary simultaneously in the conventional trapezoidal model is not always appropriate.

Figure 7.Comparison of soil and vegetation temperatures from the two models and ASTER

Table 4. The statistical items from the comparison of soil and vegetation temperatures from the two models and ASTER

\begin{tabular}{|c|c|c|c|c|c|c|c|}
\hline \multirow[t]{2}{*}{ Site } & \multirow[t]{2}{*}{ Model } & \multicolumn{3}{|c|}{ Ts } & \multicolumn{3}{|c|}{$\mathbf{T v}$} \\
\hline & & $\begin{array}{c}\operatorname{Bias}(\mathrm{K} \\
)\end{array}$ & $\operatorname{RMSE}(\mathrm{K})$ & $\begin{array}{l}\text { RMSE } \\
(\%)\end{array}$ & $\begin{array}{c}\operatorname{Bias}(\mathrm{K} \\
)\end{array}$ & RMSE (K) & RMSE (\%) \\
\hline \multirow{3}{*}{ US_Bo1 } & ESVEP & 0.19 & $2.76^{* *}$ & 10.16 & -0.83 & $2.80^{* *}$ & 9.73 \\
\hline & Conventional model & -1.86 & $3.64^{* *}$ & 13.40 & -0.91 & $2.82^{* *}$ & 9.80 \\
\hline & ESVEP & -0.10 & $2.04^{* *}$ & 7.46 & -1.63 & $2.54^{* *}$ & 10.17 \\
\hline \multirow[t]{2}{*}{ US_ARM } & Conventional model & 0.29 & $2.37^{* *}$ & 8.66 & -0.54 & $3.51^{* *}$ & 14.06 \\
\hline & ESVEP & 0.42 & $1.56^{* *}$ & 4.98 & -1.74 & $2.80^{* *}$ & 11.11 \\
\hline US_Aud & Conventional model & 0.61 & $2.29^{* *}$ & 7.31 & -3.09 & $4.62^{* *}$ & 15.49 \\
\hline
\end{tabular}

* means the result passed the significance test $\alpha=0.01$.

In total, the $T_{s}$ and $T_{v}$ are successfully separated using the two trapezoidal models, and the deviations are acceptable, which provide necessary preparation for the accurate estimation of $E T_{s}$ and $E T_{v}$. Specifically, the ESVEP model performs better and is more stable than the conventional trapezoidal model in both the $T_{s}$ and $T_{v}$ separations. Recall that some similar performances of the two models may result from the fact that the shape of the $L S T / F V C$ space in the conventional trapezoidal model in this situation approximates a triangle shape, which corresponds with the first stage of ET in the ESVEP model. The better performance of the ESVEP model may result from considering the different responses of the soil water content to the $E T_{s}$ and $E T_{v}$, which might be closer to reality.

\subsection{ET estimations from the two trapezoidal models}

With the determination of the available surface energy flux and calculation of the corresponding temperatures, $E T_{s}$ and $E T_{v}$ are parameterized by the two trapezoidal models. The total $E T\left(E T_{s}+\right.$ $E T_{v}$ ) from the two trapezoidal models is evaluated with the EC measurement corrected with the RE and BR methods, respectively. For the conventional trapezoidal model, another situation is also discussed, in which the near-surface air temperature is regarded as an alternative to the temperatures of the wet edges. Figure 8 depicts the scatterplots between the estimated ET and the EC measurement at these three sites, in which the ESVEP model, the conventional trapezoidal model and the model in another situation are represented by ESVEP, conventional model, and 
conventional model_Ta, respectively. From the figure, estimates from the ESVEP model show closer agreement with the EC measurements than that of the conventional trapezoidal model and the estimated ET from the ESVEP model and measured values are distributed around the 1:1 line on most days, regardless of when the results are compared to the measurements corrected by the RE method or the BR method. Figure 9 shows the statistical biases and RMSEs. The statistical bias, RMSE and the relative RMSE (RMSE value presented as percentage of mean ET) are displayed in Table 5.

Figure 8. Validation of estimated ET from the two trapezoidal models with EC measurements corrected with the RE method (a) (c) (e) and the BR method (b) (d) (f) at the three test sites

Table 5.The RMSE and relative RMSE of ET estimation from the two trapezoidal models compared with EC measurements corrected by the RE and the BR method

\begin{tabular}{|c|c|c|c|c|c|c|c|}
\hline Site & Model & $\begin{array}{c}\text { Bias } \\
\text { RE } \\
\left(\overline{\mathbf{W}} / \mathbf{m}^{2}\right. \\
)\end{array}$ & $\begin{array}{c}\text { RMSE_R } \\
\text { E } \\
\text { correction } \\
\mathbf{S} \\
\left(\mathbf{W} / \mathbf{m}^{2}\right) \\
\end{array}$ & $\begin{array}{c}\text { Relative } \\
\text { RMSE_RE } \\
\text { corrections } \\
\quad(\%)\end{array}$ & $\begin{array}{c}\text { Bias } \\
\mathbf{B R} \\
\left(\overline{\mathbf{W}} / \mathbf{m}^{2}\right)\end{array}$ & $\begin{array}{c}\text { RMSE_B } \\
\mathbf{R} \\
\text { correction } \\
\mathbf{S} \\
\left(\mathbf{W} / \mathbf{m}^{2}\right) \\
\end{array}$ & $\begin{array}{c}\text { Relative } \\
\text { RMSE_BR } \\
\text { corrections } \\
(\%)\end{array}$ \\
\hline \multirow{3}{*}{ US_Bo1 } & ESVEP & -6.8 & $49.8^{* * *}$ & 22.8 & -19.4 & $51.7^{* *}$ & 24.4 \\
\hline & Conventional model & 35.4 & $89.5^{* *}$ & 41.1 & 35.8 & $78.1^{* *}$ & 36.8 \\
\hline & $\begin{array}{c}\text { Conventional } \\
\text { model_Ta }\end{array}$ & -22.3 & $75.1^{* *}$ & 34.5 & -37.9 & $84.9^{* *}$ & 40.1 \\
\hline \multirow{3}{*}{$\underset{\mathbf{M}}{\mathbf{U S} \_\mathbf{A R}}$} & ESVEP & -15.6 & $58.4^{* *}$ & 24.0 & 8.6 & $53.3^{* *}$ & 24.3 \\
\hline & Conventional model & -13.1 & $72.5^{* *}$ & 29.8 & 5.6 & $70.8^{* *}$ & 32.3 \\
\hline & $\begin{array}{c}\text { Conventional } \\
\text { model_Ta }\end{array}$ & -61.0 & $82.0^{* *}$ & 33.7 & 48.6 & $77.5^{* *}$ & 45.4 \\
\hline \multirow{3}{*}{$\underset{\text { d }}{\text { US_Au }}$} & ESVEP & 12.7 & $50.6^{* *}$ & 27.2 & 2.4 & $42.6^{* *}$ & 28.1 \\
\hline & Conventional model & 15.9 & $72.0^{* *}$ & 38.7 & -7.6 & $57.5^{* *}$ & 37.9 \\
\hline & $\begin{array}{c}\text { Conventional } \\
\text { model_Ta }\end{array}$ & -26.1 & $69.0^{* *}$ & 37.1 & -32.1 & $56.2^{* *}$ & 37.1 \\
\hline
\end{tabular}

${ }_{* *}^{*}$ means the result passed the significance test $\alpha=0.01$.

Figure 9.Statistical measures for the validation of ET from the two trapezoidal models, with EC measurements corrected by the RE (a) method and the BR (b) method at the three test sites

When the results are validated by the RE corrected measurements (Figure 9(a)), ET produced by the ESVEP model has an overall bias of $-6.8 \mathrm{~W} / \mathrm{m}^{2}$ and an RMSE of $49.8 \mathrm{~W} / \mathrm{m}^{2}(22.8 \%)$ at the US_Bo1 site, a bias of $-15.6 \mathrm{~W} / \mathrm{m}^{2}$ and an RMSE of $58.4 \mathrm{~W} / \mathrm{m}^{2}(24.0 \%)$ at the US_ARM site, and a bias of $12.7 \mathrm{~W} / \mathrm{m}^{2}$ and an RMSE of $50.6 \mathrm{~W} / \mathrm{m}^{2}(27.2 \%)$ at the US_Aud site. For the conventional trapezoidal model, the estimation biases are $35.4 \mathrm{~W} / \mathrm{m}^{2},-13.1 \mathrm{~W} / \mathrm{m}^{2}$ and $-15.9 \mathrm{~W} / \mathrm{m}^{2}$ at these three sites, with RMSEs of $89.5 \mathrm{~W} / \mathrm{m}^{2}(41.1 \%), 72.5 \mathrm{~W} / \mathrm{m}^{2}(29.8 \%)$ and $72.0 \mathrm{~W} / \mathrm{m}^{2}(98.7 \%)$, respectively. In another situation of this model, the results have similar RMSEs; however, in this situation, ET is more seriously underestimated, with biases of $-22.3 \mathrm{~W} / \mathrm{m}^{2},-61.0 \mathrm{~W} / \mathrm{m}^{2}$ and -26.1 $\mathrm{W} / \mathrm{m}^{2}$ and RMSEs of $75.1 \mathrm{~W} / \mathrm{m}^{2}(34.5 \%), 82.0 \mathrm{~W} / \mathrm{m}^{2}(33.7 \%)$ and $69.0 \mathrm{~W} / \mathrm{m}^{2}(37.1 \%)$ at the US_Bo1 site, US_ARM site and US_Aud site, respectively.

When the results are validated with the BR corrected measurements (Figure 9(b)), the ESVEP model performs with biases of $-19.4 \mathrm{~W} / \mathrm{m}^{2}, 8.6 \mathrm{~W} / \mathrm{m}^{2}$ and $2.4 \mathrm{~W} / \mathrm{m}^{2}$ and with RMSEs of $51.7 \mathrm{~W} / \mathrm{m}^{2}$ 
$(24.4 \%), 53.3 \mathrm{~W} / \mathrm{m}^{2}(24.3 \%)$ and $42.6 \mathrm{~W} / \mathrm{m}^{2}(28.1 \%)$ at three test sites, respectively. For the conventional trapezoidal model, the biases are $35.8 \mathrm{~W} / \mathrm{m}^{2}, 5.6 \mathrm{~W} / \mathrm{m}^{2}$ and $-7.6 \mathrm{~W} / \mathrm{m}^{2}$, with RMSEs of $78.1 \mathrm{~W} / \mathrm{m}^{2}(36.8 \%), 70.8 \mathrm{~W} / \mathrm{m}^{2}(32.3 \%)$ and $57.5 \mathrm{~W} / \mathrm{m}^{2}(37.9 \%)$ at the US_Bo1 site, US_ARM site and US_Aud site, respectively. In another situation of the model, the estimation biases are $37.9 \mathrm{~W} / \mathrm{m}^{2},-48.6 \mathrm{~W} / \mathrm{m}^{2}$ and $-32.1 \mathrm{~W} / \mathrm{m}^{2}$, with RMSEs of $84.9 \mathrm{~W} / \mathrm{m}^{2}(40.1 \%), 77.5 \mathrm{~W} / \mathrm{m}^{2}(45.4 \%)$ and $56.2 \mathrm{~W} / \mathrm{m}^{2}(37.1 \%)$ at three test sites, respectively, still indicating serious underestimations. It was pointed out in a previous study (Tang \& $\mathrm{Li}, 2017$ ) that the use of the area-averaged air temperature would overestimate the temperature of the wet end-member/edge if the underlying surface was water-stressed, which might be the reason for the more serious underestimations. In addition, at the US_Aud site, the ET estimations are less than $0 \mathrm{~W} / \mathrm{m}^{2}$ in Figure 9 (c) on the three days (2007051, 2007090, and 2007099) when the $T_{s}$ are seriously underestimated (Figure 7 (f)). As for different sites with different climates and vegetation types, the ESVEP model performed better and more stably, showing that the ESVEP model is capable of discriminating ET for different crop types.

Further, a sensitivity analysis is performed in this study. We analyzed the relative change of ET estimation from the two trapezoidal models with the change of $T_{s}$ or $T_{v}$ by $-3 \mathrm{~K},-2 \mathrm{~K},-1 \mathrm{~K},+1 \mathrm{~K}$, $+2 \mathrm{~K},+3 \mathrm{~K}$ to its initial value, respectively. 14 days are selected when the RMSE related to the ET estimation is less than $10 \mathrm{~W} / \mathrm{m}^{2}$ compared to the BR corrected measurements and the results are presented in Figure 10. It can be found that a slight perturbation of $T_{v}$ would bring greater variation of ET than $T_{s}$ in the conventional trapezoidal model. As for the ESVEP model, the ET estimation is sensitive to $T_{s}$ in most selected days while insensitive to $T_{v}$ in most days. In the conventional trapezoid model, a $\pm 1 \mathrm{~K}$ perturbation in $T_{s}$ and $T_{v}$ produce about $10 \%$ and $20 \%$ variation in ET estimation, respectively; a $\pm 2 \mathrm{~K}$ perturbation in $T_{s}$ and $T_{v}$ produce $11 \%-28 \%$ and $22 \%-65 \%$ variation in ET estimation, respectively; a $\pm 3 \mathrm{~K}$ perturbation in $T_{s}$ and $T_{v}$ cause $20 \%-49 \%$ and $30 \%-89 \%$ variation in ET estimation, respectively. As for the ESVEP model, approximate sensitivity to $T_{s}$ is found compared to the conventional trapezoid model in the days when ET estimation is sensitive to $T_{s}$; while the perturbation in $T_{v}$ would not cause ET estimation variation in most selected days. The reason for the insensitivity to $T_{v}$ in the ESVEP model may be that the ET process is in first stage of the model in which $E T_{v}$ is estimated using $E T$ under extremely wet condition directly rather than with $T_{v}$ (Eq. (8b)).

Figure 10 Sensitivity analysis of ET estimation to the variations in $T_{S}$ and $T_{v}$ in (a) (b) the conventional trapezoid model and (c) (d) the ESVEP model

\subsection{Discussion}

The ESVEP model and conventional trapezoidal model used in this study are both two-source models, and their greatest merit lies in their ability to discriminate vegetation transpiration from soil surface evaporation when compared with single-source models. Therefore, they are more practical in agricultural applications for better allocating water resources and improving water use efficiency (Crow et al., 2008; Long et al., 2012). The results from this study and other previous studies (Zhang et al., 2008; Yang et al., 2012; Tang \& Li, 2017) have indicated that these two models both have acceptable accuracies. In fact, long term ET can also be well simulated by many models already (Miralles et al., 2016; Mueller et al., 2013; Schlesinger et al., 2014; Sutanto et al.,2014; Wei et al., 2017), however, these ETs are usually simulated with coarse resolution which are more than $50 \mathrm{~km}$ or $100 \mathrm{~km}$. Compared to two-source energy balance models, such as N95 model, the ESVEP model has slightly lower but comparable accuracy (Tang \& Li, 2017). However, 
the two-source energy balance models usually need the estimation of the parallel or series resistance network, which somewhat complicates the application of them over a wide range of surface fractional vegetation cover and soil water availability conditions. A sensitivity analysis from previous studies (Long \& Singh, 2012; Tang \& Li, 2017) suggested that the two models are most sensitive to $L S T$ from remote sensing data and are relatively not sensitive to a range of derived meteorological observations and variables (wind speed, air vapor pressure, vegetation height). However, the meteorological data requirement is still a challenge when these two models are used over large areas. Currently, several globally or regionally gridded meteorological reanalysis products may provide data inputs for the two models, indicating promise for mapping ET over large areas.

In this study, the ESVEP model performs better and is more stable than the conventional trapezoidal model in separating $E T_{s}$ and $E T_{v}$. The improvement in the ESVEP model comes from the consideration for different responses of the soil water content to $E T_{s}$ and $E T_{v}$. The difference of the two trapezoidal models which are studied in this paper is only the interpretation process for separating $E T_{s}$ and $E T_{v}$. The temperatures of four end-members in the two trapezoidal models are determined by the same method that used in the ESVEP model. And it is different in other papers in which the two models use different ways for the calculation of end-members. This is to say, the conventional trapezoidal model in our paper only use the conventional interpretation processes of ET but not the conventional method for determining the four dry/wet soil/vegetation end-members. According to the principle of the ESVEP model, it has a greater potential to enhance the effects of partitioning evapotranspiration and monitoring deep soil moisture. Thus, this model is suitable for deep root vegetation which highly depends on the soil moisture at the root zone. In additional, other previous studies (Karnieli et al., 2006; 2010) showed that when water is the limiting factor for vegetation growth, the LST/FVC relationship correlation is negative. Therefore, the ESVEP model based on LST/FVC relationship is more suitable for the areas and periods where water is the limiting factor for vegetation growth, such as in arid and semiarid areas and during the midseason (Sun et al. 2016).

As for the validation of the $E T_{s}$ and $E T_{v}$ separations, a small amount of reliable data exists. Although limited field datasets are used in some studies (Talsma et al., 2018), it has also been pointed out that it is difficult to draw definite conclusions given the paucity of the field datasets. In this study, the validations $T_{s}$ and $T_{v}$ derived from the two trapezoidal models are used as the first proof for the separation of $E T_{s}$ and $E T_{v}$. The results show that $T_{s}$ and $T_{v}$ are in good agreement with those from the ASTER data. The relatively large errors from the $T_{v}$ separations might derive from the overestimation of ASTER LST compared with the calculations from the longwave radiation measurements. In fact, the measured longwave radiations are manually observed on the ground and their measured times cannot exactly match the ASTER overpass times. Therefore, it is important to have accurate component temperatures for validation. Some studies (Song et al., 2015) have tried using simulated temperatures from the diurnal temperature cycle (DTC) model to validate the separated $T_{s}$ and $T_{v}$, which may be tested in further studies.

The total ET from the two trapezoidal models is evaluated with the EC measurements, which is regarded as another validation for the estimations of $E T_{s}$ and $E T_{v}$. For the differences between the estimated ET and measured values, several error sources cannot be neglected. The primary source should be the scale mismatch between the ET datasets, namely, the spatial representativeness of the EC-derived ET is different with a MODIS pixel resolution of $1 \mathrm{~km}$. However, the flux data $(L E$ and $H$ ) used in this study are all from EC systems which are located about $2 \mathrm{~m}$ height above 
the ground. Therefore, the foot prints of the measured flux data are overall all within the MODIS pixel and the uncertainty caused by the foot print from the EC measurements is relatively small. Moreover, the observation time is not totally matched. In general, MODIS-based prediction is usually instantaneous value at the satellite overpass time, while the ET measurement is usually half-hour averaged value. Errors in the remotely sensed data and meteorological records can also lead to errors. The results of the available energy retrievals showed that, there is a fairly close agreement between the retrievals and the measurements, but the RMSE values are almost half of those related to the ET estimations. Therefore, there is still room to improve the estimation accuracies of remote sensing parameters. Neglecting of interception evaporation maybe also one of the reasons for the errors of total ET estimates in some models, however, only clear days are selected for the estimations of ET when using the two trapezoidal models and there is no precipitation, thus, the interception is very small in this study.

In addition, ASTER data is used to validate estimated $T_{s}$ and $T_{v}$ from the two trapezoidal models in this study, and the two trapezoidal models are applied at three flux sites and not large spatial regions due to the insufficient data from the ASTER. The compounding effects from the spatial heterogeneity of the soil moisture content and vegetation cover may also affect the estimations, which may also need further investigation.

\section{Summary and conclusion}

In this study, the $E T_{s}$ and $E T_{v}$ are estimated using the conventional trapezoidal model and the ESVEP model. These two trapezoidal models are applied at three AmeriFlux sites with different climate types in the USA. Due to lack of reliable data for the validation of these individual fluxes, the $T_{s}$ and $T_{v}$, which include important information related to $E T_{s}$ and $E T_{v}$, are separated first using the two trapezoid models and compared with the corresponding temperatures from ASTER. In addition, the total ET is validated with the EC measurements after correction of the energy imbalance with the RE and BR methods. The results show that the ESVEP model reproduces $T_{s}$, with an RMSE of 1.56-2.7 K (4.98-10.16 \%), and $T_{v}$, with an RMSE of 2.54-2.80 K (9.73-11.11\%). The conventional trapezoidal model has an RMSE of 2.26-3.64 K (7.31-13.40\%) for $T_{s}$ separation and an RMSE of 2.82-4.62 K (9.80-15.49 \%) for $T_{v}$ separation. Compared to the RE corrected measurements, the ESVEP model estimates ET with overall RMSEs of $49.8 \mathrm{~W} / \mathrm{m}^{2}(22.8 \%), 58.4$ $\mathrm{W} / \mathrm{m}^{2}(24.0 \%)$ and $50.6 \mathrm{~W} / \mathrm{m}^{2}(27.2 \%)$ at three test sites; and the conventional trapezoidal model estimates ET with RMSEs of $89.5 \mathrm{~W} / \mathrm{m}^{2}(41.1 \%), 72.5 \mathrm{~W} / \mathrm{m}^{2}(29.8 \%)$ and $72.0 \mathrm{~W} / \mathrm{m}^{2}(38.7 \%)$. Compared to the BR corrected measurements, the RMSEs are $51.7 \mathrm{~W} / \mathrm{m}^{2}(24.4 \%), 53.3 \mathrm{~W} / \mathrm{m}^{2}$ $(24.3 \%)$ and $42.6 \mathrm{~W} / \mathrm{m}^{2}(28.1 \%)$ for the ESVEP model, and $78.1 \mathrm{~W} / \mathrm{m}^{2}(36.8 \%), 70.8 \mathrm{~W} / \mathrm{m}^{2}$ $(32.3 \%)$ and $57.5 \mathrm{~W} / \mathrm{m}^{2}(37.9 \%)$ for the conventional trapezoidal model. When the wet edges are calculated using the near-surface air temperatures, the conventional trapezoidal model has more serious underestimations of the ET. The sensitivity analysis shows that ET estimation is similar sensitive to $T_{\mathrm{S}}$ in both two trapezoidal model and is less sensitive to $\mathrm{T}_{\mathrm{V}}$ in the ESVEP model than in the conventional trapezoidal model.

Therefore, the ESVEP model performs better and is more stable than the conventional trapezoid and less sensitive to $T_{v}$ variation in ET estimation. For the wide range of applications of the ESVEP model in the future, globally or regionally gridded meteorological reanalysis products may be taken as input data; the accuracy related to the remote sensing data parameterization should be improved, and space and time matching among all data should also be taken into further consideration. 


\section{Acknowledgements}

We thank the AmeriFlux data resource (http://ameriflux.lbl.gov/) provided by the U.S. Department of Energy's Office of Science, the MODIS resource (https://ladsweb.modaps.eosdis.nasa.gov/search/) and the ASTER resource (https://search.earthdata.nasa.gov/search/). Three anonymous reviewers are acknowledged for their valuable comments that have greatly improved the paper. This work was supported by the by National Natural Science Foundation of China (41571351, 41571352, 41571367), the Strategic Priority Research Program of the Chinese Academy of Sciences (XDA19040403), the Youth Innovation Promotion Association CAS under 2015039, and China Scholarship Council.

\section{References}

Allen, R. G., Pereira, L. S. D., Raes, and Smith, M. (1998) “Crop evapotranspiration-Guidelines for computing crop water requirements”, FAO Technical Paper 56, Food and Agricultural Organization of the United Nations, Rome.

Allen, R. G., Tasumi, M., \& Trezza, R. (2007). Satellite-based energy balance for mapping evapotranspiration with internalized calibration (METRIC)-Model. Journal of irrigation and drainage engineering, 133(4), 380-394. http://dx.doi.org/10.1061/(ASCE)07339437(2007)133:4(380).

Anderson, M. C., Allen, R. G., Morse, A., \& Kustas, W. P. (2012). Use of Landsat thermal imagery in monitoring evapotranspiration and managing water resources. Remote Sensing of Environment, 122, 50-65. http://dx.doi.org/10.1016/j.rse.2011.08.025.

Anderson, M. C., Norman, J. M., Kustas, W. P., Houborg, R., Starks, P. J., \& Agam, N. (2008). A thermal-based remote sensing technique for routine mapping of land-surface carbon, water and energy fluxes from field to regional scales. Remote Sensing of Environment, 112, 42274241. https://doi.org/10.1016/j.rse.2008.07.009.

Anderson, M.C., Norman, J.M., Mecikalski, J.R., Otkin, J.A., Kustas, W.P., (2007). A climatological study of evapotranspiration and moisture stress across the continental United States based on thermal remote sensing: 1. Model formulation. Journal of Geophysical Research: Atmosphere, 112, D10117. http://dx.doi.org/10.1029/2006JD007506.

Carlson, T. (2007). An overview of the "triangle method" for estimating surface evapotranspiration and soil moisture from satellite imagery. Sensors, 7, 1612-1629. http://dx.doi.org/10.3390/s7081612.

Carlson, T. N. (2013). Triangle models and misconceptions. International Journal of Remote Sensing Applications, 3(3), 155-158.

Crow, W. T., Kustas, W. P., \& Prueger, J. H. (2008). Monitoring root-zone soil moisture through the assimilation of a thermal remote sensing-based soil moisture proxy into a water balance model. Remote Sensing of Environment, 112(4), 1268-1281. http://dx.doi.org/10.1016/j.rse.2006.11.033.

Di, S. C., Li, Z. L., Tang, R., Wu, H., Tang, B. H., \& Lu, J. (2015). Integrating two layers of soil moisture parameters into the MOD16 algorithm to improve evapotranspiration estimations. 
International journal of remote sensing, 36(19-20), 4953-4971. https://doi.org/10.1080/01431161.2015.1040136.

Fisher, J.B., Melton, F., Middleton, E., Hain, C., Anderson, M., Allen, R. et al. (2017). The future of evapotranspiration: global requirements for ecosystem functioning, carbon and climate feedbacks, agricultural management, and water resources. Water Resources Research. 53, 2618-2626. http://dx.doi.org/10.1002/2016WR020175.

Gebremichael, M., \& Barros, A. P. (2006). Evaluation of MODIS gross primary productivity (GPP) in tropical monsoon regions. Remote Sensing of Environment, 100(2), 150-166. https://doi.org/10.1016/j.rse.2005.10.009.

Good, S. P., Moore, G. W., \& Miralles, D. G. (2017). A mesic maximum in biological water use demarcates biome sensitivity to aridity shifts. Nature ecology \& evolution, 1(12), 1883. http://dx.doi.org/10.1038/s41559-017-0371-8.

Jiang, L., \& Islam, S. (2003). An intercomparison of regional latent heat flux estimation using remote sensing data. International Journal of Remote Sensing, 24(11), 2221-2236. http://dx.doi.org/10.1080/01431160210154821.

Jiménez-Muñoz, J. C., Sobrino, J. A., Gillespie, A., Sabol, D., \& Gustafson, W. T. (2006). Improved land surface emissivities over agricultural areas using ASTER NDVI. Remote Sensing of Environment, 103(4), 474-487. https://doi.org/10.1016/j.rse.2006.04.012.

Karnieli, A., Agam, N., Rachel T., Pinker, Anderson, M., Marc L., Garik G. Gutman, Natalya P., and Goldberg A., "Use of NDVI and land surface tmperature for drought assessment: Merits and limitations," Journal of Climate, 23 (3), 618-633, https:// dx.doi.org/10.1175/2009JCLI2900.1.

Karnieli, A., Bayasgalan, M. , Bayarjargal, Y. , Agam, N. , Khudulmur, S. , \& Tucker, C. J. . (2006). Comments on the use of the vegetation health index over mongolia. International Journal of Remote Sensing, 2017-2024. http://dx.doi.org/10.1080/01431160500121727.

Kustas, W. P., \& Norman, J. M. (2000). A two-source energy balance approach using directional radiometric temperature observations for sparse canopy covered surfaces. Agronomy Journal, 92(5), 847-854. http://dx.doi.org/10.2134/agronj2000.925847x.

Leng, P., Li, Z. L., Duan, S. B., Tang, R., \& Gao, M. F. (2017). A Method for Deriving All-Sky Evapotranspiration From the Synergistic Use of Remotely Sensed Images and Meteorological Data. Journal of Geophysical Research: Atmospheres, 122(24). https://doi.org/10.1002/2017JD027880.

Li, Z. L., Tang, B. H., Wu, H., Ren, H., Yan, G., Wan, Z. \& Sobrino, J. A. (2013). Satellite-derived land surface temperature: Current status and perspectives. Remote Sensing of Environment, 131, 14-37. https://doi.org/10.1016/j.rse.2012.12.008.

Li, Z. L., Tang, R., Wan, Z., Bi, Y., Zhou, C., Tang, B. Yan, G., \& Zhang, X. (2009). A review of current methodologies for regional evapotranspiration estimation from remotely sensed data. Sensors, 9(5), 3801-3853. http://dx.doi.org/10.3390/s9050380. 
Liang, X., Lettenmaier, D. P., Wood, E. F., \& Burges, S. J. (1994). A simple hydrologically based model of land surface water and energy fluxes for general circulation models. Journal of Geophysical Research, 99(D7), 14415. http://dx.doi.org/10.1029/94JD00483

Long, D., \& Singh, V. P. (2012). A two-source trapezoid model for evapotranspiration (TTME) from satellite imagery. Remote Sensing of Environment, 121, 370-388. https://doi.org/10.1016/j.rse.2012.02.015.

Miralles, D. G., Jiménez, C., Jung, M., Michel, D., Ershadi, A., \& Mccabe, M. F., et al. (2016). The wacmos-et project \& ndash; part 2: evaluation of global terrestrial evaporation data sets. Hydrology and Earth System Sciences, 20(2), 823-842. http://dx.doi.org/10.5194/hess-20823-2016.

Moran, M. S., Clarke, T. R., Inoue, Y., \& Vidal, A. (1994). Estimating crop water deficit using the relation between surface-air temperature and spectral vegetation index. Remote sensing of environment, 49(3), 246-263. http://dx.doi.org/10.1016/0034-4257(94)90020-5.

Mueller, B., et al. (2013), Benchmark products for land evapotranspiration: LandFlux-EVAL multi-dataset synthesis, Hydrology and Earth System Sciences, 17(10), 3707-3720. http://dx.doi.org/10.5194/hess-17-3707-2013

Nishida, K., Nemani, R. R., Running, S. W., \& Glassy, J. M. (2003). An operational remote sensing algorithm of land surface evaporation. Journal of Geophysical Research: Atmospheres, 108(D9). https://doi.org/10.1029/2002JD002062.

Norman, J. M., \& Campbell, G. S. (1998). An introduction to environmental biophysics. Springer, New York.

Norman, J. M., Kustas, W. P., \& Humes, K. S. (1995). A two-source approach for estimating soil and vegetation energy fluxes in observations of directional radiometric surface temperature. Agricultural and Forest Meteorology, 77(3-4), 263-293. .

Sánchez, J. M., Kustas, W. P., Caselles, V., \& Anderson, M. C. (2008). Modelling surface energy fluxes over maize using a two-source patch model and radiometric soil and canopy temperature observations. Remote Sensing of Environment, 112, 1130-1143. https://doi.org/10.1016/j.rse.2007.07.018.

Schlesinger, W. H., and S. Jasechko (2014). Transpiration in the global water cycle, Agricultural and Forest Meteorology, 189-190, 115-117. http://dx.doi.org/10.1016/j.agrformet.2014.01.011.

Schlesinger, W., \& Jasechko, S. (2014). Transpiration in the global water cycle. Agricultural and Forest Meteorology, 189-190, 115-117. https://doi.org/10.1016/j.agrformet.2014.01.011.

Song, L., Liu, S., Kustas, W. P., Zhou, J., \& Ma, Y. (2015). Using the surface temperature-albedo space to separate regional soil and vegetation temperatures from ASTER data. Remote Sensing, 7(5), 5828-5848. http://dx.doi.org/10.3390/rs70505828.

Stoy, P. C., Mauder, M., Foken, T., Marcolla, B., Boegh, E., Ibrom, A., et al. (2013). A data-driven analysis of energy balance closure across FLUXNET research sites: The role of landscape scale heterogeneity. Agricultural and Forest Meteorology, 171, 137-152. https://doi.org/10.1016/j.agrformet.2012.11.004. 
Sun, H. (2016). Two-stage trapezoid: A new interpretation of the land surface temperature and fractional vegetation coverage space. IEEE Journal of Selected Topics in Applied Earth Observations and Remote Sensing, 9(1), 336-346. http://dx.doi.org/10.1109/JSTARS.2015.2500605.

Sun, H., Wang, Y., Liu, W., Yuan, S., \& Nie, R. (2017). Comparison of three theoretical methods for determining dry and wet edges of the LST/FVC space: Revisit of method physics. Remote Sensing, 9(6), 528. http://dx.doi.org/10.3390/rs9060528

Sutanto, S. J., Van den Hurk, B., Dirmeyer, P. A., Seneviratne, S. I., Röckmann, T., Trenberth, K. E., \& Hoffmann, G. (2014). HESS Opinions" A perspective on isotope versus non-isotope approaches to determine the contribution of transpiration to total evaporation". Hydrology and Earth System Sciences, 18(8), 2815-2827. https://doi.org/10.5194/hess-18-2815-2014.

Talsma, C. J., Good, S. P., Jimenez, C., Martens, B., Fisher, J. B., Miralles, D. G., \& Purdy, A. J. (2018). Partitioning of evapotranspiration in remote sensing-based models. Agricultural and Forest Meteorology, 260, 131-143. https://doi.org/10.1016/j.agrformet.2018.05.010.

Tang, R., \& Li, Z. L. (2017). An end-member-based two-source approach for estimating land surface evapotranspiration from remote sensing data. IEEE Transactions on Geoscience and Remote Sensing, 55(10), 5818-5832. http://dx.doi.org/10.1109/TGRS.2017.2715361.

Tang, R., Li, Z. L., \& Sun, X. (2013). Temporal upscaling of instantaneous evapotranspiration: An intercomparison of four methods using eddy covariance measurements and MODIS data. Remote Sensing of Environment, 138, 102-118. https://doi.org/10.1016/j.rse.2013.07.001.

Tang, R., Li, Z. L., \& Tang, B. (2010). An application of the Ts-VI triangle method with enhanced edges determination for evapotranspiration estimation from MODIS data in arid and semiarid regions: Implementation and validation. Remote Sensing of Environment, 114(3), 540551. http://dx.doi.org/10.1016/j.rse.2009.10.012.

Tang, R., Li, Z.-L., Tang, B., and Wu, H., (2015b). Interpretation of surface temperature/vegetation index space for evapotranspiration estimation from SVAT modeling," in Proc. IEEE International. Geoscience and Remote Sensing Symposium. (IGARSS), Milan, Italy, pp. 20282030. https://doi.org/10.1109/IGARSS.2015.7326197.

Tang, R., Shao, K., Li, Z. L., Wu, H., Tang, B. H., Zhou, G., \& Zhang, L. (2015a). Multiscale validation of the 8-day MOD16 evapotranspiration product using flux data collected in China. IEEE Journal of Selected Topics in Applied Earth Observations and Remote Sensing, 8(4), 1478-1486. http://dx.doi.org/10.1109/JSTARS.2015.2420105.

Twine, T. E., Kustas, W. P., Norman, J. M., Cook, D. R., Houser, P. R., Meyers, T. P., et al. (2000). Correcting eddy-covariance flux underestimates over a grassland. Agricultural and Forest Meteorology, 103, 279-300. https://doi.org/10.1016/S0168-1923 (00)00123-4.

Wan, Z., \& Dozier, J. (1996). A generalized split-window algorithm for retrieving land-surface temperature from space. IEEE Transactions on geoscience and remote sensing, 34(4), 892905. https://doi.org/10.1109/36.508406.

Wang, K., \& Dickinson, R. E. (2012). A review of global terrestrial evapotranspiration: Observation, modeling, climatology, and climatic variability. Reviews of Geophysics, 50(2). https://doi.org/10.1029/2011RG000373. 
Wang, K., Li, Z., \& Cribb, M. (2006). Estimation of evaporative fraction from a combination of day and night land surface temperatures and NDVI: A new method to determine the PriestleyTaylor parameter. Remote Sensing of Environment, 102(3-4), 293-305. http://dx.doi.org/10.1016/j.rse.2006.02.007.

Wang, W., Huang, D., Wang, X. G., Liu, Y. R., \& Zhou, F. (2010). Estimate soil moisture using trapezoidal relationship between remotely sensed land surface temperature and vegetation index. Hydrology and Earth System Sciences Discussions, 7(6), 8703-8740.

Wei, Z., Yoshimura, K., Wang, L., Miralles, D. G., Jasechko, S., \& Lee, X. (2017). Revisiting the contribution of transpiration to global terrestrial evapotranspiration. Geophysical Research Letters, 44(6), 2792-2801. http://dx.doi.org/10.1002/2016GL072235.

Yang, Y., Su, H., Zhang, R., Tian, J., \& Li, L. (2015). An enhanced two-source evapotranspiration model for land (ETEML): Algorithm and evaluation. Remote Sensing of Environment, 168, 54-65. https://doi.org/10.1016/j.rse.2015.06.020.

Zhang, K., Kimball, J. S., \& Running, S. W. (2016). A review of remote sensing based actual evapotranspiration estimation. Wiley Interdisciplinary Reviews: Water, 3(6), 834-853. https://doi.org/10.1002/wat2.1168.

Zhang, R., Tian, J., Su, H., Sun, X., Chen, S., \& Xia, J. (2008). Two improvements of an operational two-layer model for terrestrial surface heat flux retrieval. Sensors, 8(10), 61656187. http://dx.doi.org/10.3390/s8106165.

Zhang, Y., Chiew, F.H.S., Peña-Arancibia, J., Sun, F., Li, H., Leuning, R., 2017. Global variation of transpiration and soil evaporation and the role of their major climate drivers. Journal of Geophysical Research: Atmospheres. 122, 6868-6881. http://dx.doi.org/10.1002/ 2017JD027025 


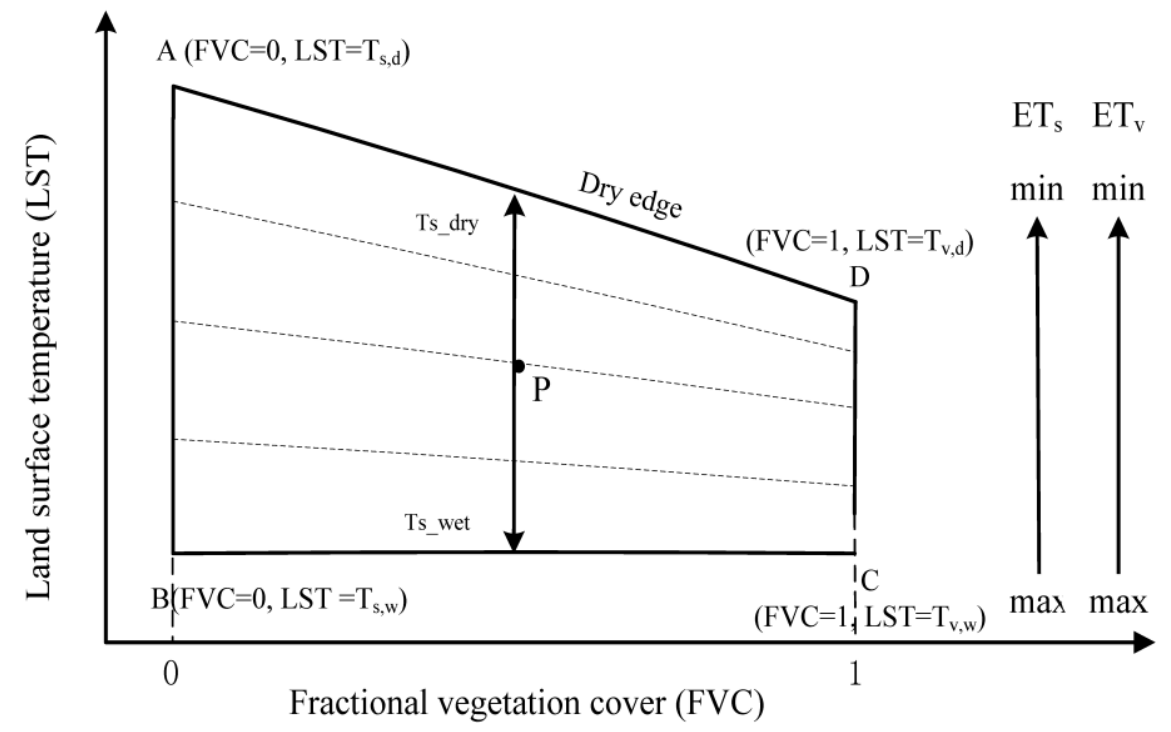

(a)

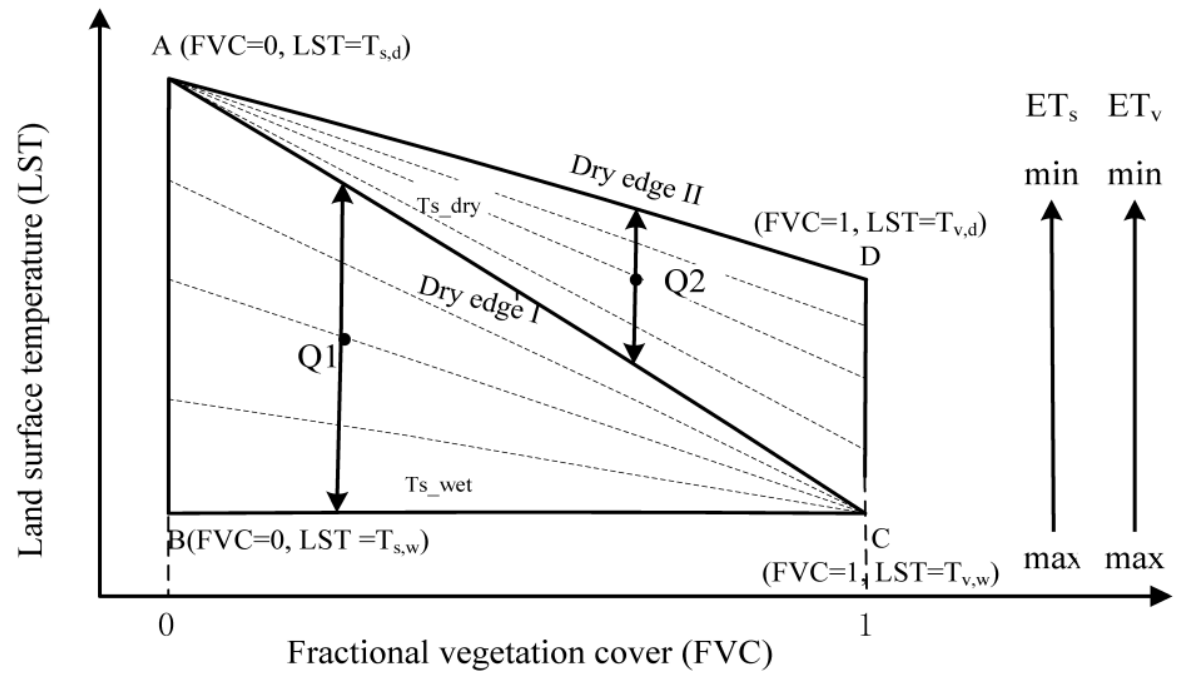

(b) 


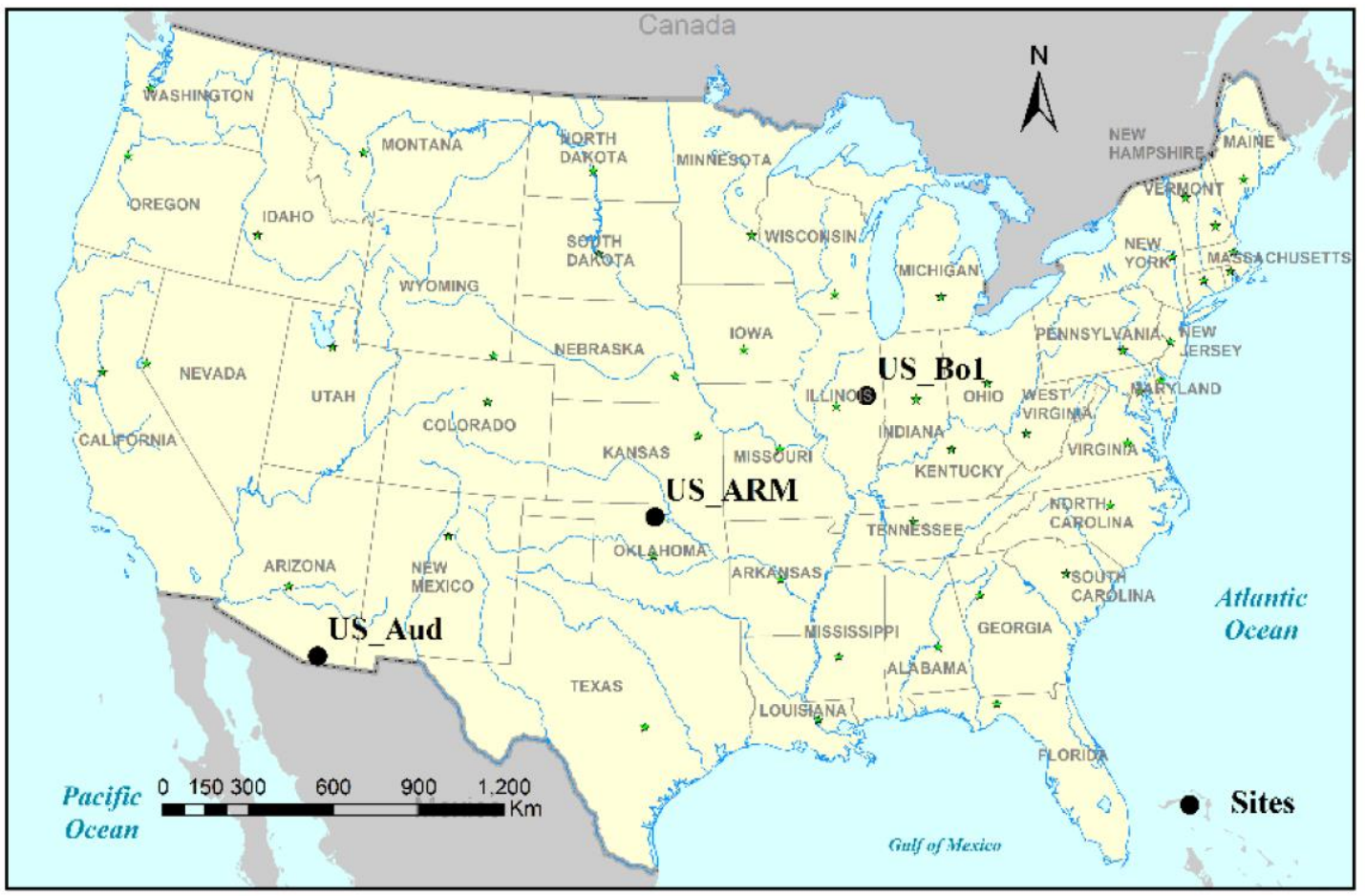

790 


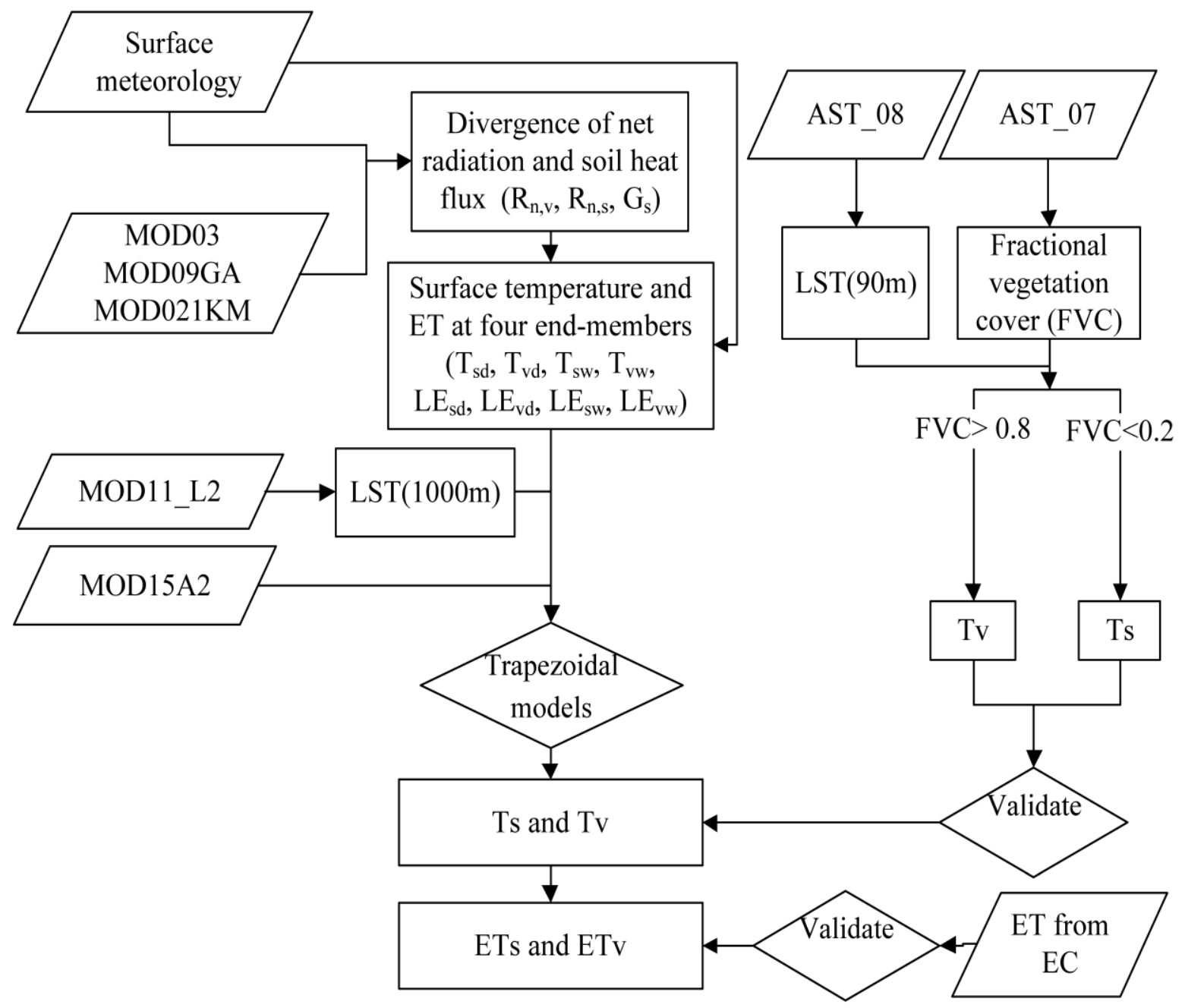




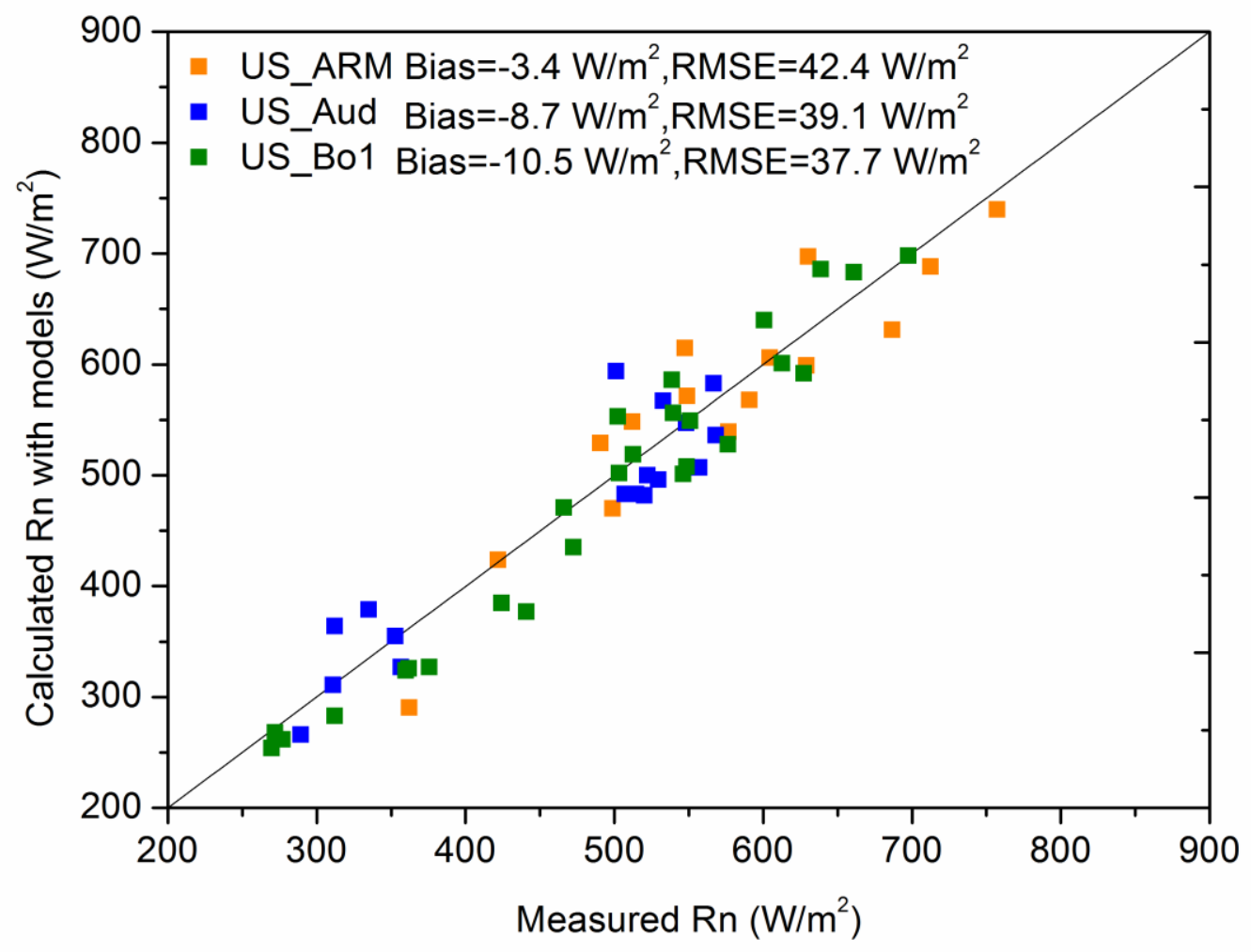

796 
799

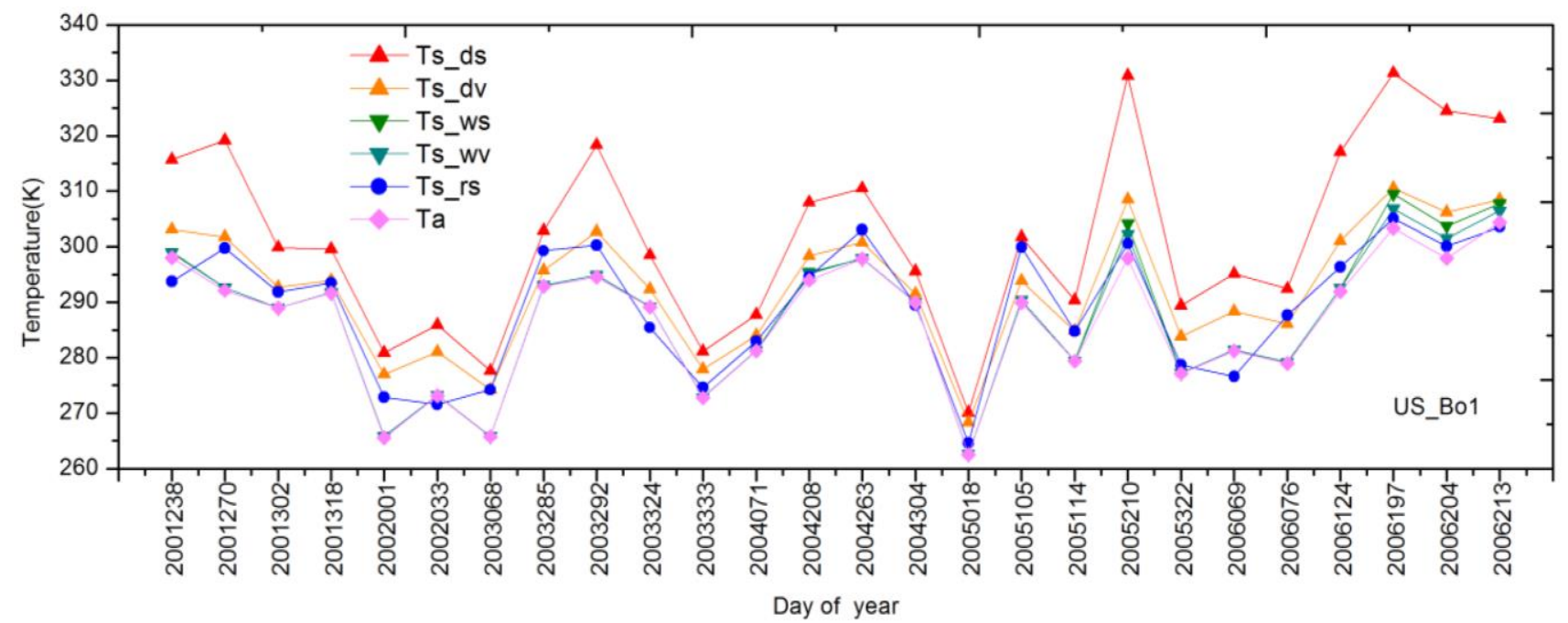

(a)

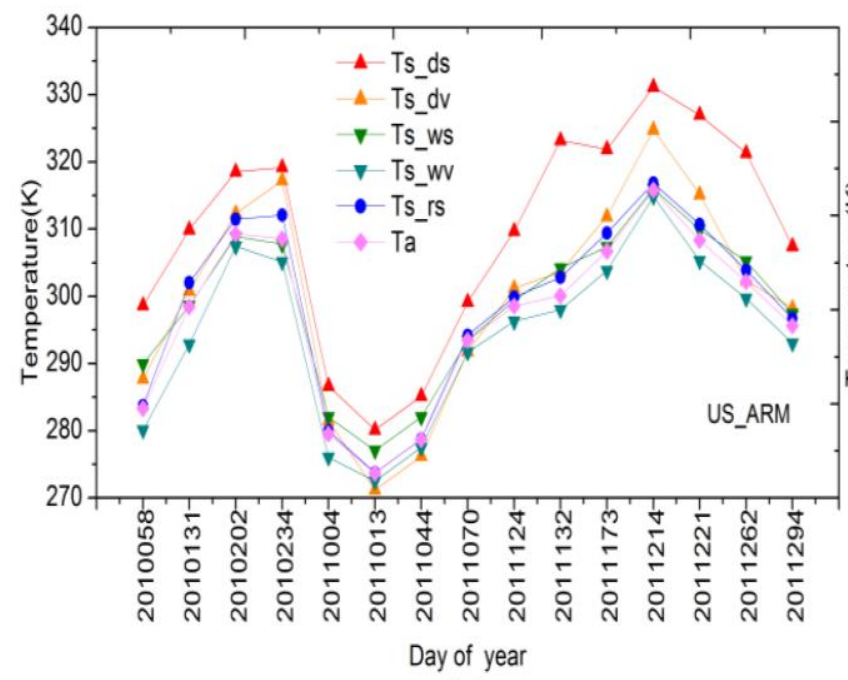

(b)

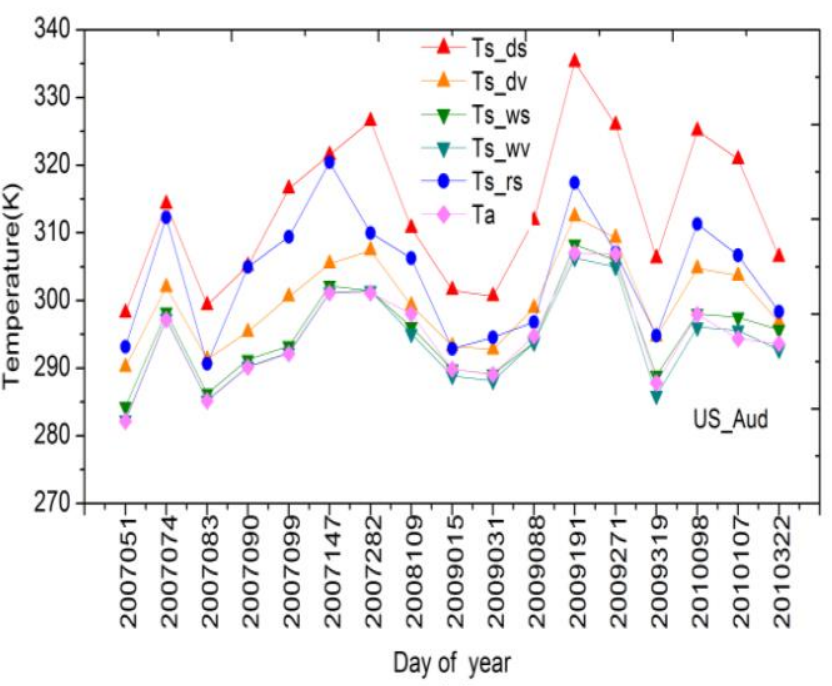

(c)
Figure 5 
$801 \quad$ Figure 6

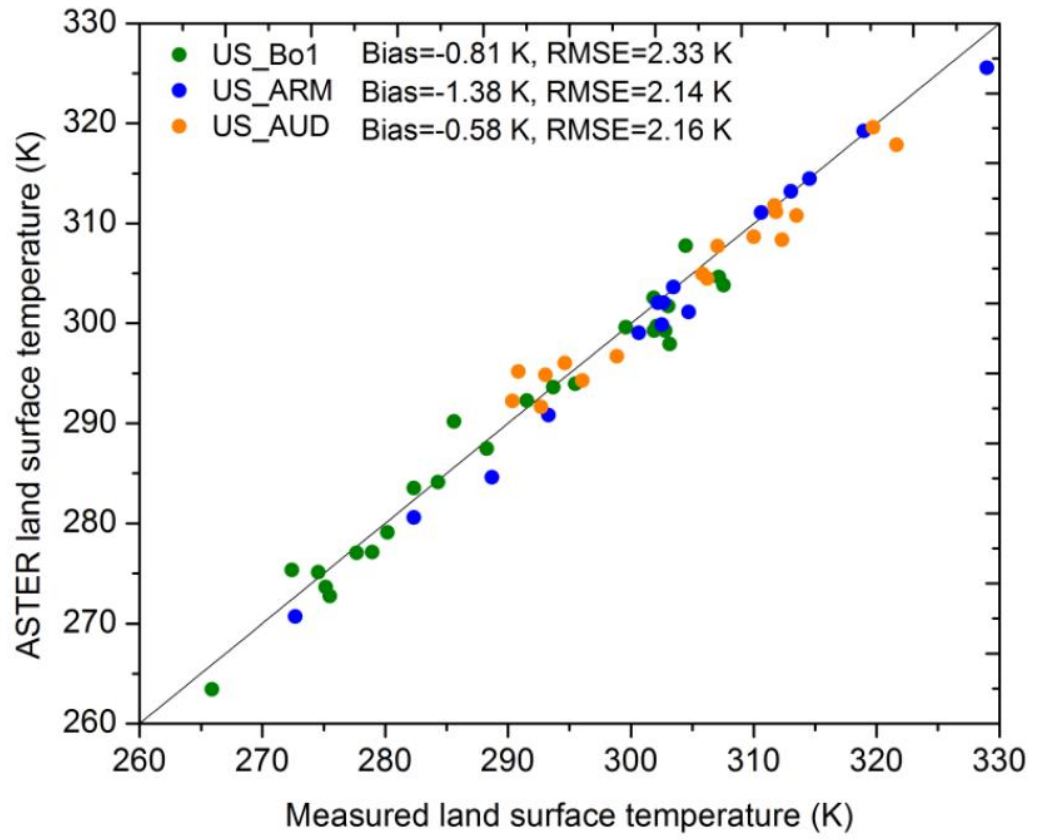

802 
Figure 7

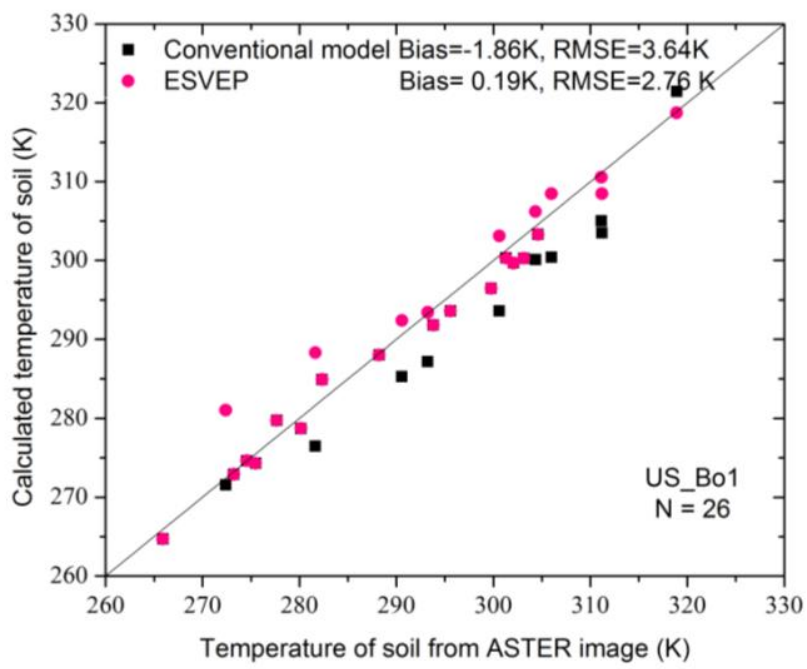

(a)

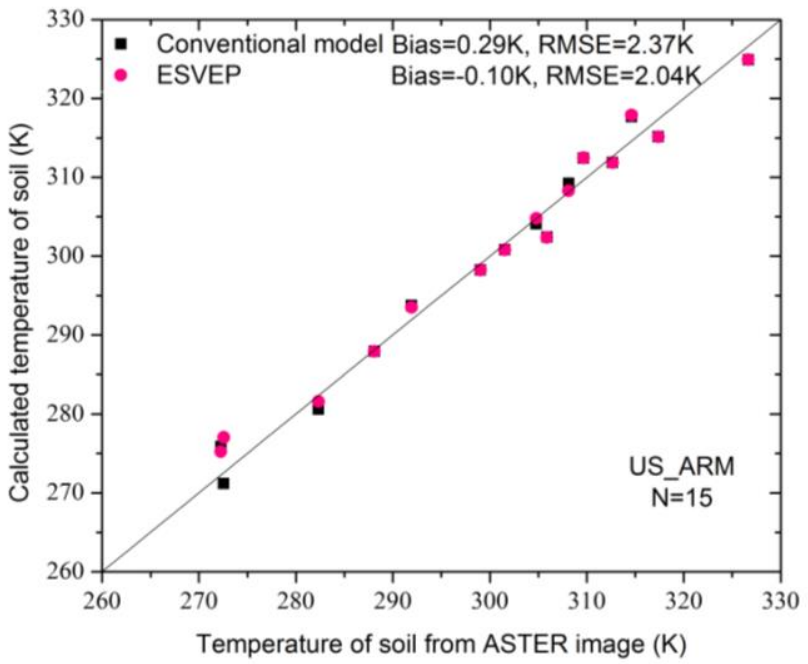

(c)

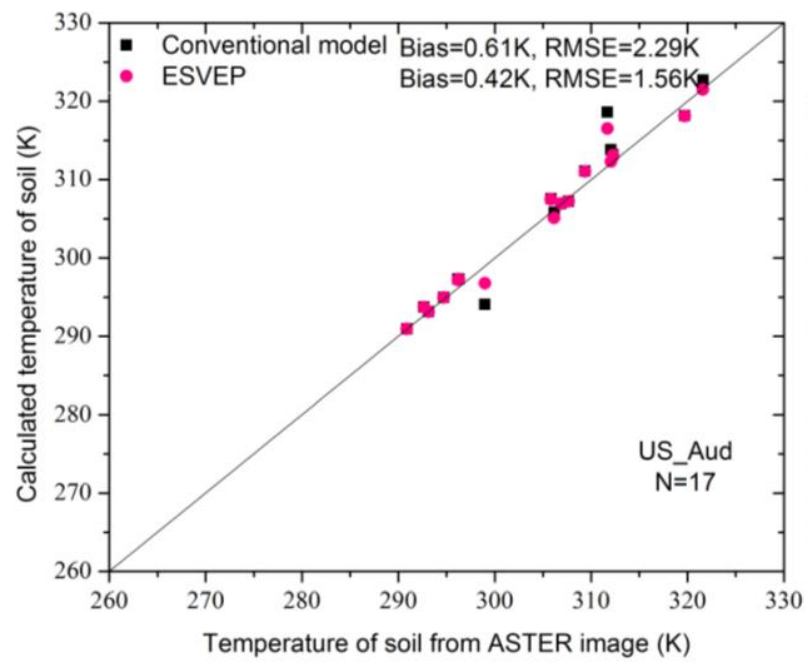

804

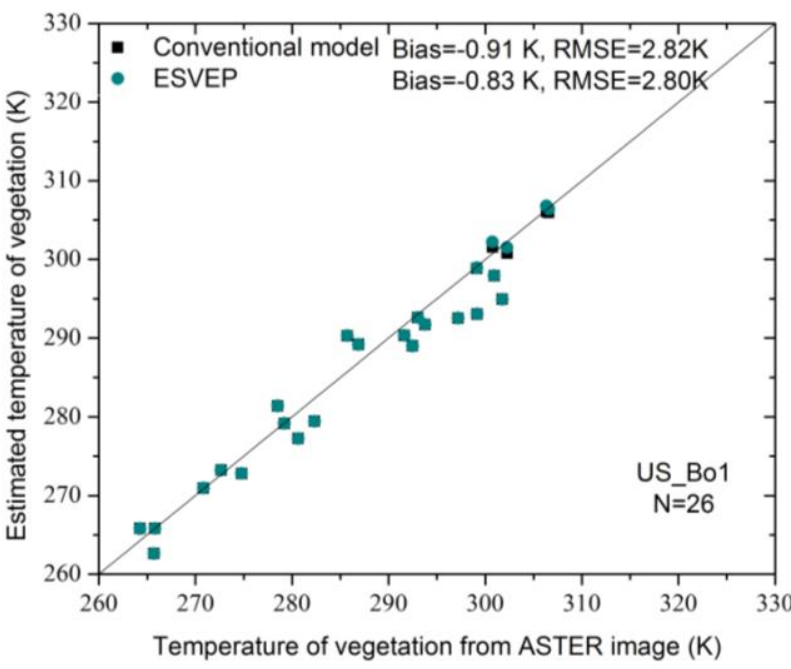

(b)

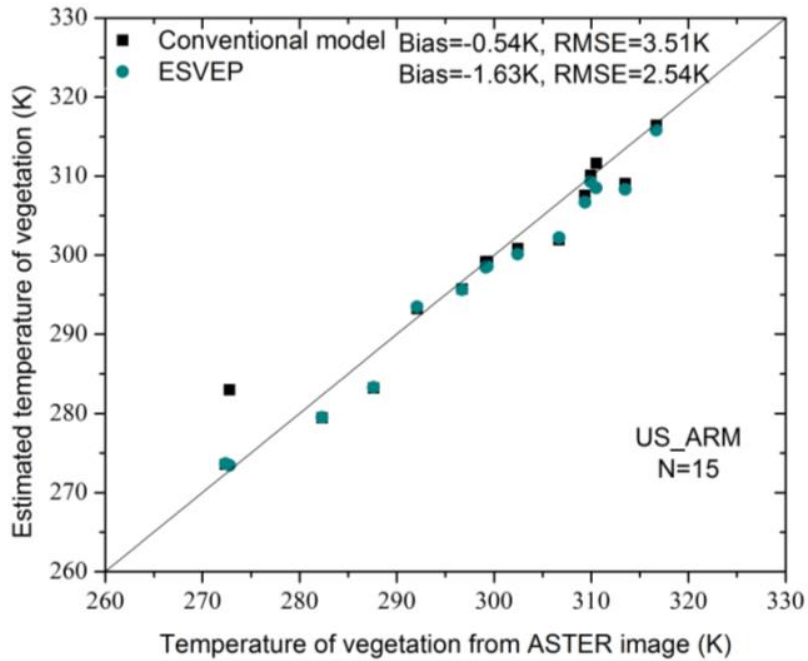

(d)

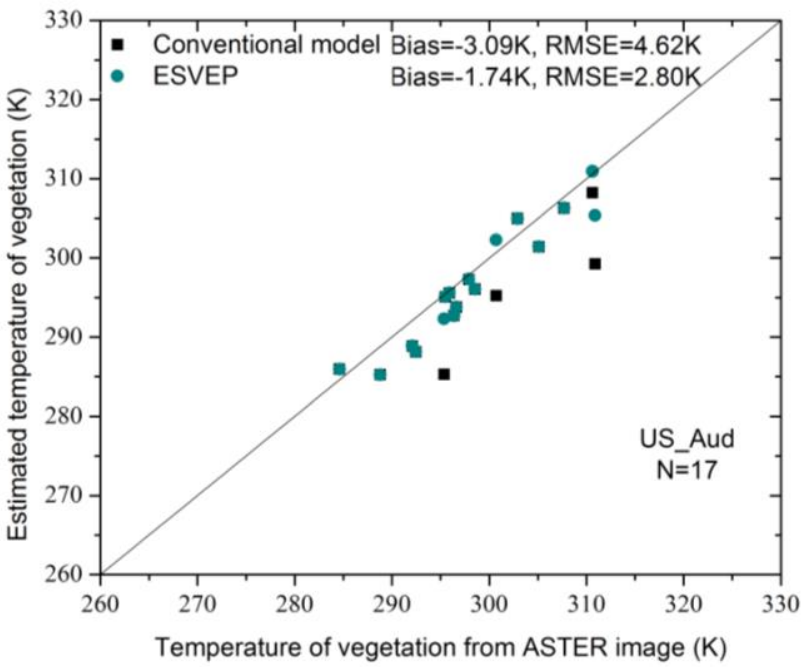

(f) 
Figure 8

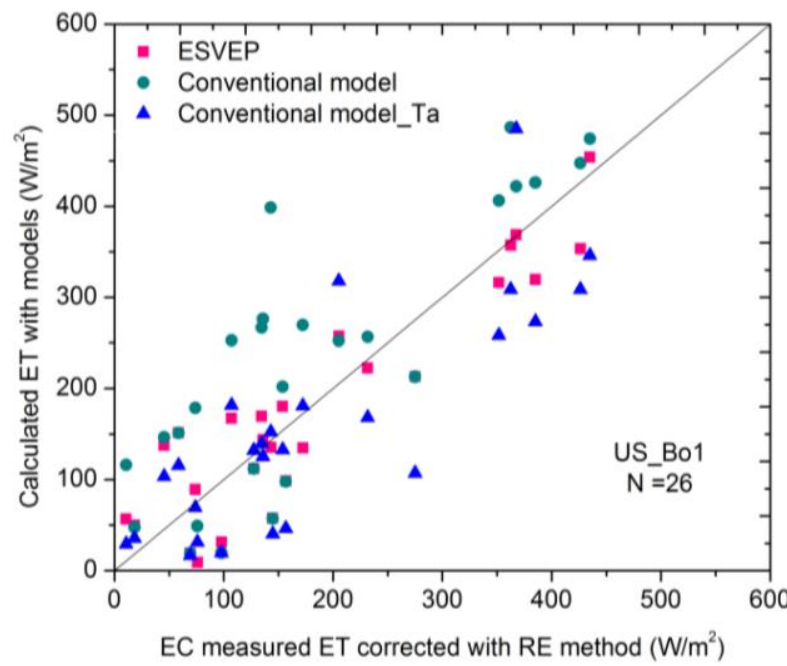

(a)

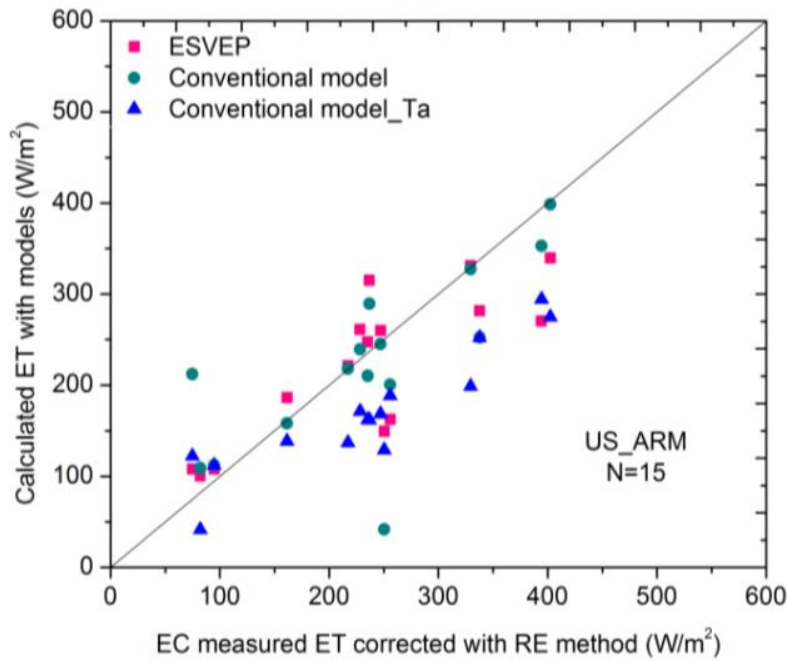

(c)

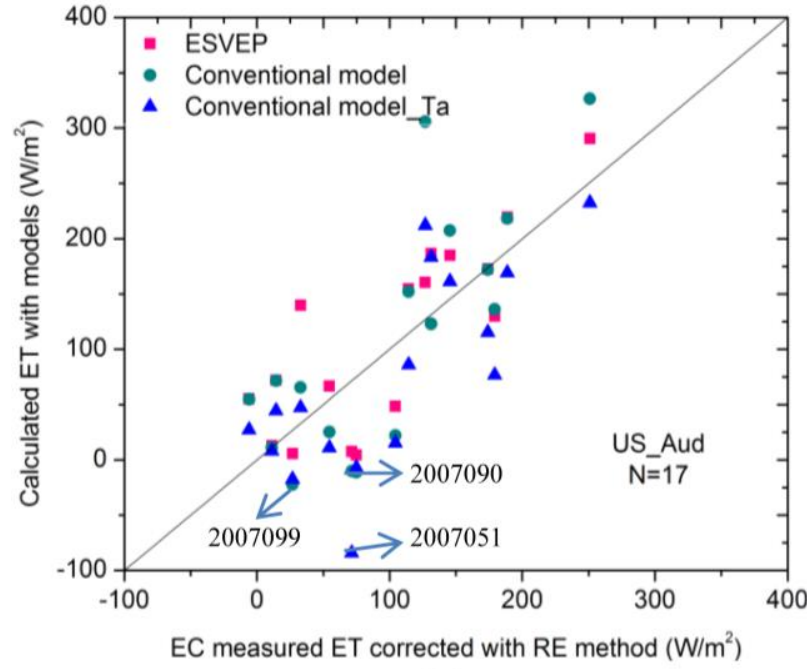

806

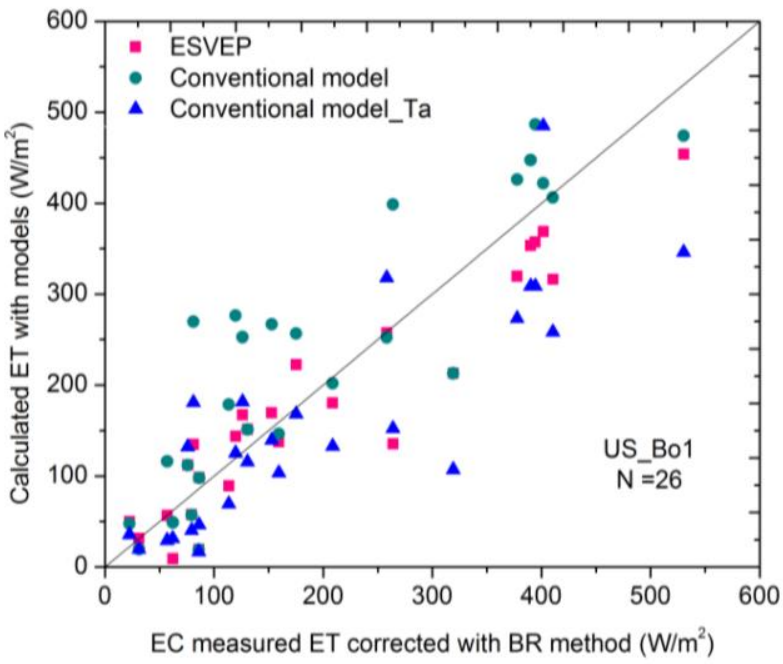

(b)

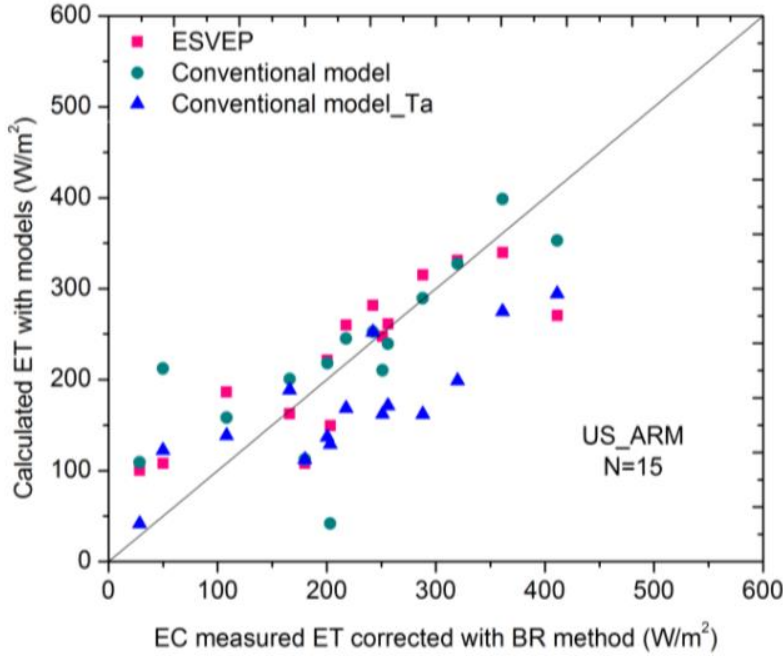

(d)

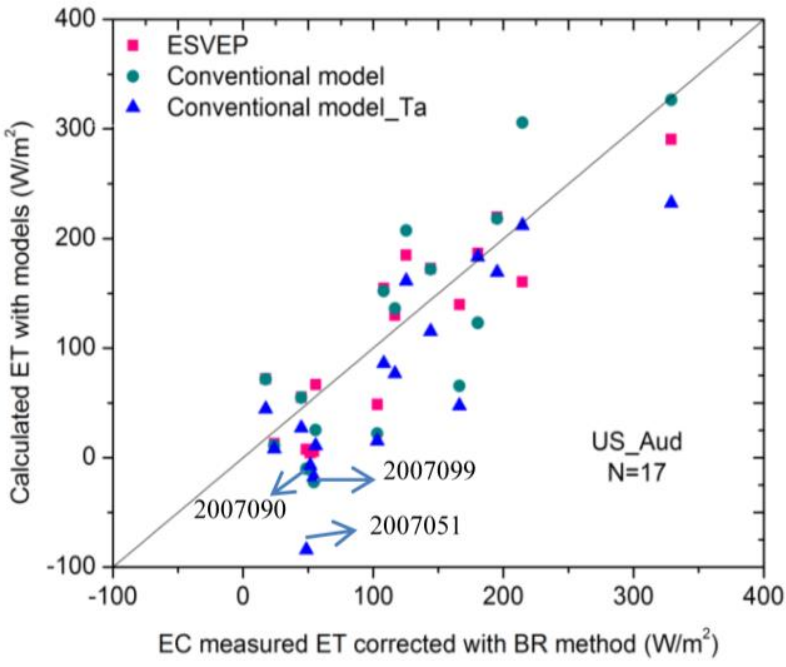

(f) 
808

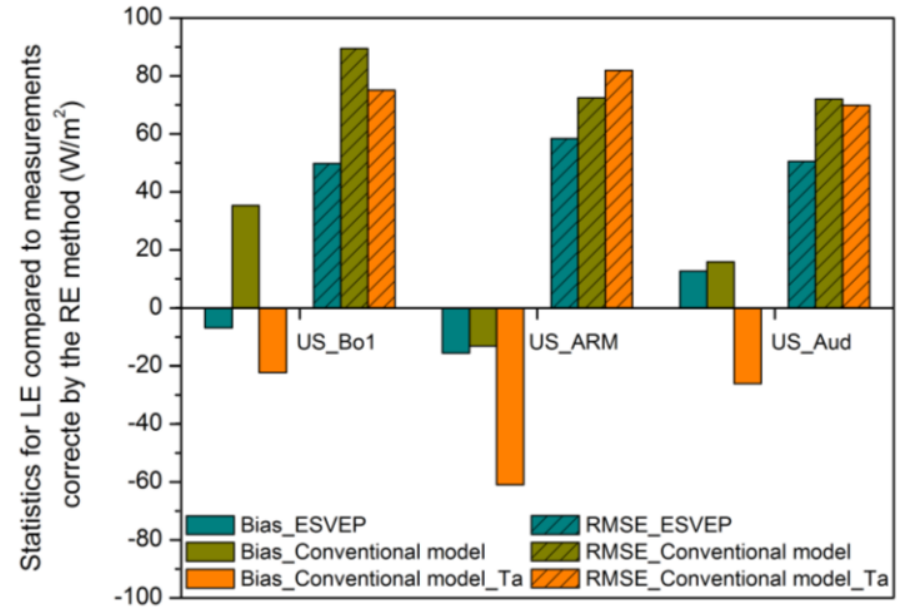

(a)

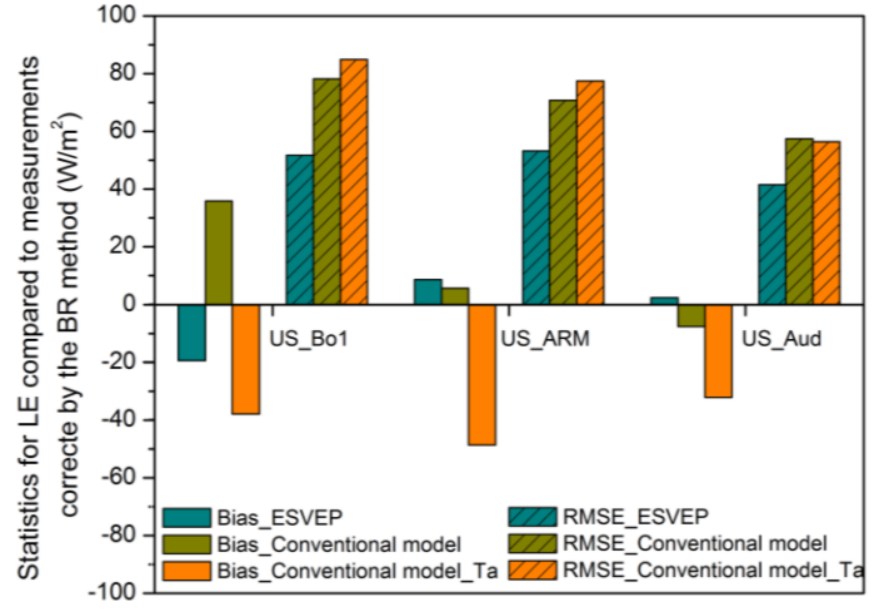

(b) 
810

Figure 10

811

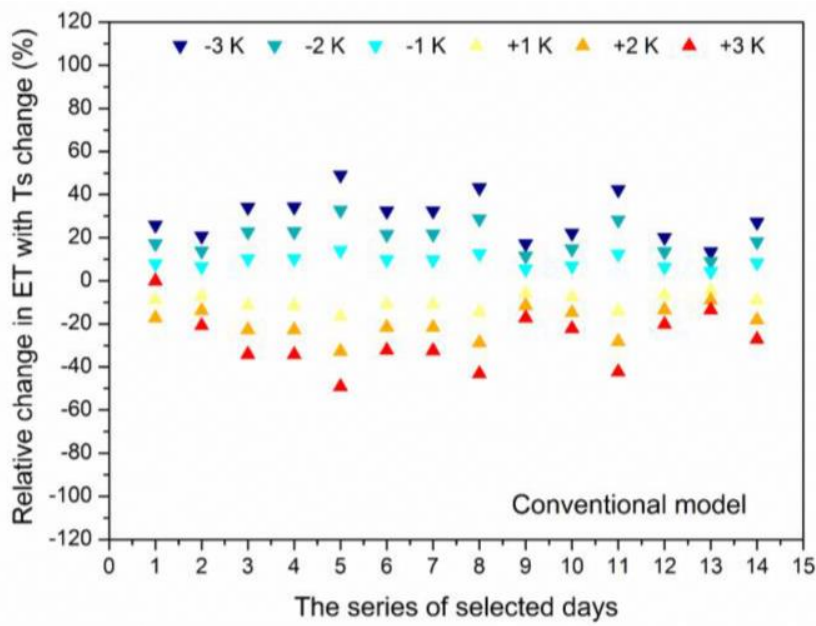

(a)

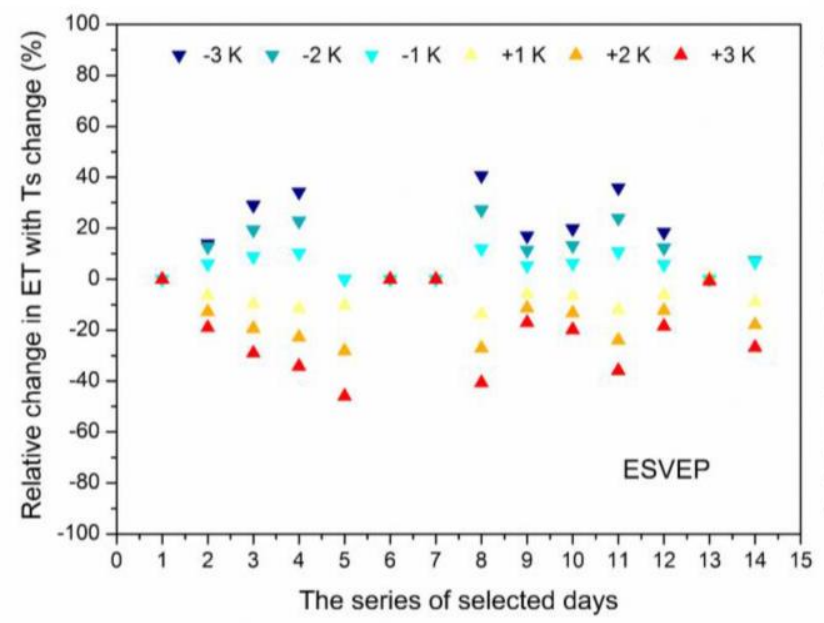

812

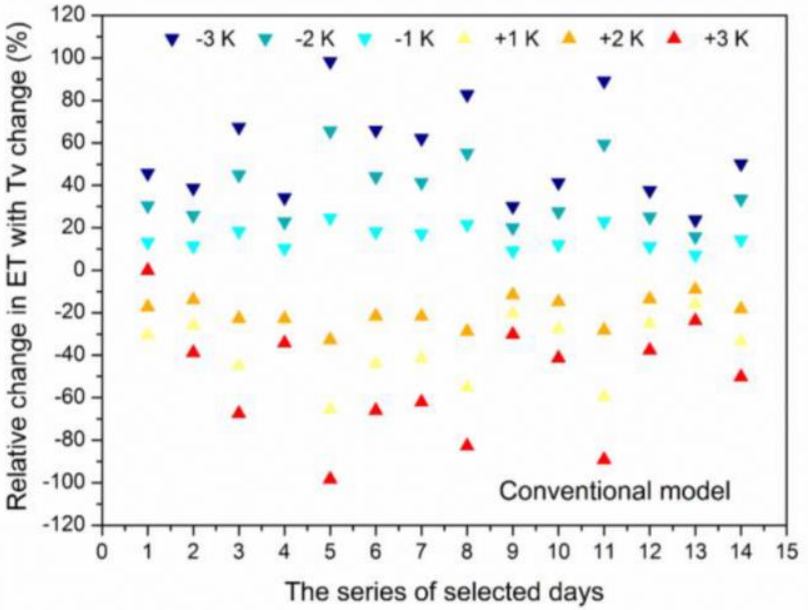

(b)

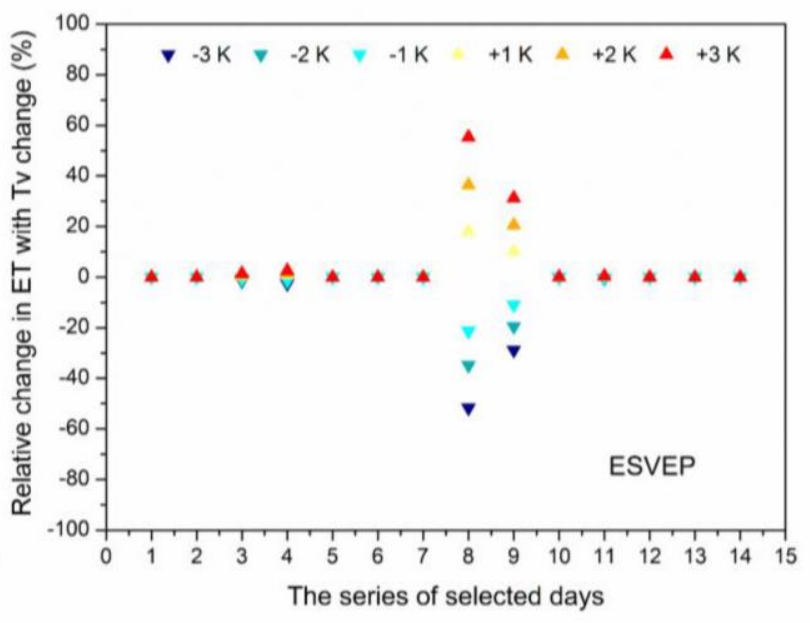

(d) 